Article

\title{
Accessibility, Demography and Protection: Drivers of Forest Stability and Change at Multiple Scales in the Cauvery Basin, India
}

\section{Nikhil Lele ${ }^{1, *}$, Harini Nagendra ${ }^{1,2}$ and Jane Southworth ${ }^{3}$}

1 Ashoka Trust for Research in Ecology and the Environment, Royal Enclave, Srirampura, Jakkur P.O., Bangalore 560064, India; E-Mail: nagendra@indiana.edu

2 Center for the Study of Institutions, Population, and Environmental Change (CIPEC), Indiana University, 408 North Indiana Avenue, Bloomington, IN 47408, USA

3 Department of Geography, University of Florida, 3141 Turlington Hall, Gainesville, FL 32611, USA; E-Mail: jsouthwo@ufl.edu

* Author to whom correspondence should be addressed; E-Mail: mail.nikhillele@gmail.com; Tel.: +91-80-23635555; Fax: +91-80-23530070.

Received: 25 November 2009; in revised form: 7 January 2010 / Accepted: 8 January 2010 / Published: 12 January 2010

\begin{abstract}
The Cauvery basin of Karnataka State encompasses a range of land cover types, from dense forest areas and plantations in the Western Ghats hills, to fertile agricultural lands in the river valley. Recent demographic changes, rapid economic development and urbanization have led to the conversion of vast stretches of forested land into plantations and permanent agriculture. We examine the human drivers of forest cover change between 2001 and 2006, using MODIS $250 \mathrm{~m}$ data at multiple spatial scales of nested administrative units i.e., districts and taluks. Population density does not emerge as a major driver of forest distribution or deforestation. Protected areas and landscape accessibility play a major role in driving the distribution of stable forest cover at different spatial scales. The availability of forested land for further clearing emerges as a major factor impacting the distribution of deforestation, with new deforestation taking place in regions with challenging topography. This research highlights the importance of using a regional approach to study land cover change, and indicates that the drivers of forest change may be very different in long settled landscapes, for which little is known in comparison to frontier forests.
\end{abstract}


Keywords: land use/land cover change drivers; deforestation; demography; tropical forests; India

\section{Introduction}

Deforestation constitutes one of the most serious environmental challenges the World faces today. The consequences of forest clearing are well documented and severe, ranging from biodiversity extinctions to global warming, soil erosion and increased flooding [1]. The impact of deforestation has been particularly intense in the tropics, where much of the world's biodiversity is concentrated [2], and which is being degraded at alarming rates each year [3]. Landscapes originally covered largely by forests have been steadily encroached upon to make way for agriculture, pastures and settlements [4].

Responding to this critical issue, the field of land change science has made significant progress in understanding, documenting and describing the driving forces that contribute to deforestation $[1,4]$. Amongst the prominent factors that impact tropical deforestation, population, accessibility and the presence of protected areas stand out as critical $[1,5]$. Since humans are the primary agents responsible for forest change, increasing human population has long been considered a major driver of deforestation $[1,6,7]$. Accessibility of forests has also been shown to consistently impact the nature and extent of forest change. When forests are easy to access, either because they are located at lower elevations or can be easily approached through road and rail networks, they tend to suffer higher levels of human impact, while forests that are less accessible, located at higher elevations, and/or distant from roads, are often less impacted [8-10]. Finally, protected areas also play a major role in limiting forest clearing. While their impact on human lives and livelihoods is being increasingly questioned, parks have managed to protect many tropical forests from further clearing [11-13].

Nevertheless, several questions and puzzles remain, notably those related to variations in the rates and drivers of deforestation across different regions, and at different spatial scales. The rather simplistic linkage of population density with deforestation fails to recognize that the relationship between humans and their environment is complex, and mediated by a number of factors. While landscape accessibility is critical, institutions can play a major role in limiting or accelerating the rate of change in accessible parts of the landscape [14]. Linkages between population and forest decline can also be moderated by many other critical variables, notably by institutions and markets $[4,5,15,16]$.

Many of these questions can be better understood by adopting a regional, multi-scalar approach to the study of deforestation. The majority of current research on the drivers of deforestation comes from detailed studies of single landscapes, with descriptive accounts of the drivers that give rise to forest change in particular contexts $[1,4,5,17,18]$. Yet there can be substantial spatial variation in forest change within landscapes, which is often ignored. Even within a landscape undergoing overall deforestation, there are often some areas where forest cover is protected or even regenerating, while other sections of the landscape are being cleared of trees $[3,12]$. Analogous to this, there is substantial regional variation in the extent and spatial pattern of deforestation as well as in the dominant drivers of change $[4,18]$. In particular, while the drivers of deforestation have been extensively researched in Latin America, the Amazon and South East Asia, the human dominated landscapes of South Asia have 
been relatively poorly researched [18,19]. Investigating drivers of deforestation at multiple scales enables a better understanding of drivers of change - and to understand the reasons for variability in the direction or extent of forest change between different parts of a landscape [14,20]. As such, the scale of investigation is critical, as variables which impact forest change at larger scales often differ from those which play a role at more local scales [15,21]. Finally, given that the purpose of much of this research is to provide directions for policy, regional multi-scalar studies of change are also critical. Most effective management plans are developed at regional scales that require an appropriate understanding of how to deal with variations in biophysical, socioeconomic and institutional conditions within a region $[22,23]$.

In the new millennium, the advent of satellites that cover large spatial extents, such as AVHRR (Advanced Very High Resolution Radiometer) images which are available at a resolution of $1 \mathrm{~km}$ and cover spatial extents (swath widths) of $6,400 \mathrm{~km}$, SPOT (Satellite Pour l'Observation de la Terre)-4 and SPOT-5 data at a resolution of $1 \mathrm{~km}$ covering 2,250 km, AWiFS (Advanced Wide Field Sensor) at a resolution of $56 \mathrm{~m}$ covering $740 \mathrm{~km}$, and MODIS (Moderate Resolution Imaging Spectroradiometer) images at a resolution of $250-500 \mathrm{~m}$ covering an extent of $2,330 \mathrm{~km}$, has greatly increased the possibility of conducting such large scale, regional, multi-scalar studies of the drivers of forest change [3,12,24-26]. While AVHRR data has been the most frequently used for regional studies of land cover change [2,3,12], the coarse resolution of these images at $1 \mathrm{~km}$, and errors caused by reliance on the Normalized Difference Vegetation Index (NDVI) for land cover mapping, limit their reliability and scope, particularly in regions with variable topography and persistent cloud cover [28,29]. Although medium resolution satellite platforms like Landsat TM, Landsat ETM+ and IRS LISS (Linear Imaging Self-Scanning Sensor) 4 provide data of higher spatial resolution and better quality, these images cover much smaller spatial extents ranging from 140-185 km [26], and require labor intensive processing and mosaicing of multiple adjacent scenes for regional studies of land cover change, which limit their utility for such purposes [22,29].

The availability of MODIS data at spatial resolutions ranging from 250-1,000 m, carrying information from multiple spectral bands including the derived NDVI, was designed to address this issue. MODIS provides data at a spatial and temporal resolution appropriate for regional studies of land cover change, and has greatly improved the ability of land change scientists to conduct regional studies of deforestation [27,28,30]. These data are available for free download, in an easy-to-use form with atmospheric calibration and geographic registration already conducted on images, making these particularly attractive for use [22,29].

This paper investigates the use of MODIS data for the study of deforestation at a regional scale in southern India. India, with its densely populated landscapes, poses a particular challenge to those interested in the dynamics of forest change. In comparison to other parts of the world including Latin America, South America and Africa, or even to other parts of Asia such as East and South East Asia, there have been few studies on the drivers of forest change in this region [18,19]. More research is required to understand the patterns and processes that influence forest change in this subcontinent. Across much of the Indian subcontinent, forests and humans coexist in close proximity, and indeed, have done so for centuries. Rural settlements dominate large parts of the region, inhabited by communities who are highly dependent on forest products for subsistence as well as for their livelihoods. These are landscapes of contrast, where it is common to find long standing traditional 
institutions of forest management coexisting with large scale forest logging, or government protected areas located alongside clearings for large infrastructure projects [14,31].

This research focuses on a large river sub-basin in southern India, the Cauvery river basin, to study the dynamics of forest change between 2001 and 2006. The study area contains the cities of Bangalore and Mysore and their surroundings, which have experienced substantial changes in forest cover in recent years due to rapid growth and industrialization, and typify the accelerated impacts of globalization experienced by much of the Indian landscape in recent years. We adopt a multi-scale approach, where we examine changes in the entire study area-covering about $55,000 \mathrm{~km}^{2}$ —and within districts and taluks (administrative sub-divisions) nested within this area. We have three main objectives. First, we seek to understand the extent and rate of deforestation in recent years in this region, a fertile alluvial plain which has witnessed substantial conflicts over water and land in recent years. Second, we seek to understand how the direction and intensity of forest change relates to population, accessibility, and the presence of protected areas. Finally, we wish to assess whether the significance and strength of these relationships changes with spatial scale. Given the criticality of this water basin for southern India, our results have significant implications for conservation planning and landscape management in the Indian context. Further, these results will help inform the larger debate on the nature, relative strength and scale-dependent relationships between drivers of deforestation at a regional scale — an issue which has been insufficiently addressed so far, particularly for South Asia.

\section{Materials and Methods}

\subsection{Study Area}

The southern Indian state of Karnataka covers an area of about $192,000 \mathrm{~km}^{2}$, comprising about $6 \%$ of the total land area of the country [32]. The $8^{\text {th }}$ largest state in India in terms of size, and the 9th largest state in terms of population, the state harbors a rich diversity of flora and fauna, with over $20 \%$ of its land area covered by forests. Yet, while rich in natural resources, forest clearing is accelerating, and so too are its impacts on environment, ecology, and quality of life. Karnataka has experienced tremendous growth and change over time, largely driven in recent years by the technology sector, and exemplifies the tensions between development and conservation experienced by much of the Indian landscape in recent years [33].

The Cauvery river is one of India's largest rivers, having shaped lands, lives and livelihoods in southern India for centuries. The fourth largest river in South India, it originates in the Western Ghats, and travels for over $800 \mathrm{~km}$ across the states of Karnataka, Kerala, Tamil Nadu and the Union Territory of Pondicherry, before draining into the Bay of Bengal. About half of this journey takes place in Karnataka, where the river's fertile basin encourages the growth of forests, agriculture, and industry, which coexist in an uneasy, rapidly changing relationship. Rural and urban areas are intermingled in this landscape, with the rural population in the Karnataka Cauvery basin comprising about $60 \%$ of the total population [34]. This region has witnessed rapid conversion of forested land to non-forest land uses such as agriculture, plantations and urban areas. Recent and rapid economic growth has led to additional pressure on this area. There is an urgent need to document changes in forest cover in this region, and to identify the main drivers of this change. 


\subsection{Methods}

MODIS $250 \mathrm{~m}$ resolution monthly data and 16 day Normalized Difference Vegetation Index (NDVI) composites were downloaded from the US National Aeronautics and Space Administration (NASA) website for 2001 and 2006. A hybrid approach to classification was adopted, combining the use of NDVI thresholds with unsupervised classification to separate forested areas from non-forested areas. We selected the month of February, which is cloud free and coincides with the fallow, post-harvest, low biomass season for many locally predominant agricultural crops, to generate NDVI values. Pixels with NDVI values above 0.5 were classified as forest. This threshold value of 0.5 was selected with reference to existing maps of protected areas which contain moist evergreen forests, as values above this threshold predominantly identified this forest category.

Next, pixels with NDVI values between 0.42 and 0.5 were identified as areas with moderate vegetation biomass, which could belong to forests, plantations, orchards or agricultural areas with standing crops. To separate these categories, we conducted an unsupervised classification for these pixels only, masking out all other parts of the image. The unsupervised classification used four band MODIS data from the blue, green, red and near infra-red bands from two months for each year-one month from the post-monsoon season, when evergreen and deciduous trees are in leaf, and one month from the pre-monsoon dry season, when deciduous trees have largely shed their leaves. We selected data from the months of December and April for 2001, and January and April for 2006, according to the availability of high quality (low-haze) images for each year.

Unsupervised classification was conducted using the ISODATA algorithm [35], grouping pixels into 100 classes. These classes were aggregated into forest (predominantly moist deciduous forest, along with a few patches of moist evergreen and dry deciduous forest) and non-forest (predominantly plantations and orchards, along with high biomass agricultural crops like sugarcane). Aggregation of classes was based on visual comparisons with existing maps of protected areas and with Survey of India 1:50,000 topographic sheets on which plantation boundaries were marked. We found this approach to have satisfactorily identified the moist deciduous and evergreen forests in the study area, but to have largely left out dry deciduous and thorny scrub forests, with lower biomass levels. In order to classify these forest types, we selected all pixels with NDVI values lower than 0.42 (in the 16 day February NDVI composite), and conducted an unsupervised classification into 50 classes using the pre-monsoon and post-monsoon data combinations described above. These clusters were aggregated following a similar approach into two classes - forests (primarily dry deciduous and thorny scrub forests, as well as some patches of moist deciduous forest) and non-forest (primarily young plantations, young orchards and agricultural crops). Detailed inputs from seven ecologists familiar with different parts of the study area helped us to identify areas that were incorrectly classified, in particular providing us with information on recent areas with agriculture and plantations that were missing from older vegetation maps of the area.

Such an approach, of unsupervised classification into a large number of clusters followed by aggregation into a small set of final land cover types, is often followed to classify moderate resolution satellite imagery covering large regions over which detailed ground information is not available [25,36;also as reviewed in 24]. Assessments of classification accuracy are challenging for a landscape of this size, covering an area of almost $55,000 \mathrm{~km}^{2}$, and with pixel sizes of $250 \mathrm{~m}$ where 
mixed pixel issues become significant. This is a limitation common to large regional studies, where ground truthing cannot be used for accuracy assessment, unless alternate, reliable large scale maps are available for cross-referencing and comparison [24,37]. As recent, fine scale remotely sensed land cover maps are unavailable for this region, this approach is not possible here, and in any case, has problems of interpretation unless the images compared are similar in image dates, training samples used to generate classifications, and land cover classes [22,38,39]. We use visual comparisons with older maps that cover parts of the landscape, and verification from experts to verify that our classification has led to satisfactory representation of the forest cover in this region.

Forest cover maps of 2001 and 2006 were overlaid to create forest change trajectories. This enables us to identify areas of stable forest (forested in 2001 and 2006), stable non-forest (non-forest in 2001 and 2006), and separate these from areas of change, i.e., deforestation (forest in 2001 but non-forested in 2006) and reforestation (non-forested in 2001 but forested in 2006). Such an approach enables us to focus on spatial patterns of change, and understand the dynamics of forest change in this area. Since our main interest is in identifying the drivers of forest change and because deforestation is the primary trend in this landscape, we focus on the stable forest and deforestation categories in this analysis. The distribution of stable forest was calculated as a percentage of the total area for each district and taluk. The distribution of deforestation was assessed in two ways. First, as with stable forest, deforestation was calculated as a percentage of the total area for each district/taluk. In addition, since the area of forest available for further conversion may have an influence on deforestation, we also calculated deforestation as a percentage of the stable forest area in 2001 for each district/taluk.

Information on forest change was regressed with altitude, population and the percentage of land in protected areas, to assess the ability of these variables to explain changes observed in forest cover. These regressions were conducted at the scale of districts (the administrative scale nested within the state of Karnataka) and taluks (the administrative level nested within districts), to additionally assess if the relationships observed changed in significance, direction or intensity with change in spatial scale. The sample size of the analysis at the district scale was too small to allow for accurate assessments of violation of assumptions of linear regression. At the taluk scale, where sample size permits this, we conducted a careful assessment to look for violation of regression assumptions. We looked at the distribution of residuals to check for violation of assumptions of normality, linearity and homoskedasticity, and looked at the Cook's distance to identify extreme outliers. Demographic data on population was obtained from the Government of India's 2001 census. While it would have been useful to additionally include data on demographic changes between 2001 and 2006, such data was not available for this study area and could not be used. Information on mean altitude for districts and taluks was obtained from the $90 \mathrm{~m}$ resolution Digital Elevation Model of the Shuttle Radar Topographic Mission of NASA.

\section{Results and Discussion}

\subsection{Forest Change at the Scale of the Study Region}

The river basin spreads across 8 districts and 51 taluks of Karnataka, covering $54,577 \mathrm{~km}^{2}$ (Figure 1). The Cauvery River originates in the hilly Western Ghats, and enters a landscape with broad fertile alluvial plains interspersed with gently rolling hills. A range of land covers and land uses co-exist. The 
Kodagu district, where the Cauvery River originates, is dominated by moist evergreen and deciduous forests along with coffee and spice plantations. The basin area includes the large urban centers of Bangalore and Mysore, rapidly urbanizing smaller towns, fertile, irrigated areas in Mandya district, and water deprived agriculture in Hassan district. To the north, a section of Tumkur is separated from the rest of the district by the Chitradurga district boundary and the Andhra Pradesh state boundary.

Figure 1. Study area, with protected area boundaries overlaid.

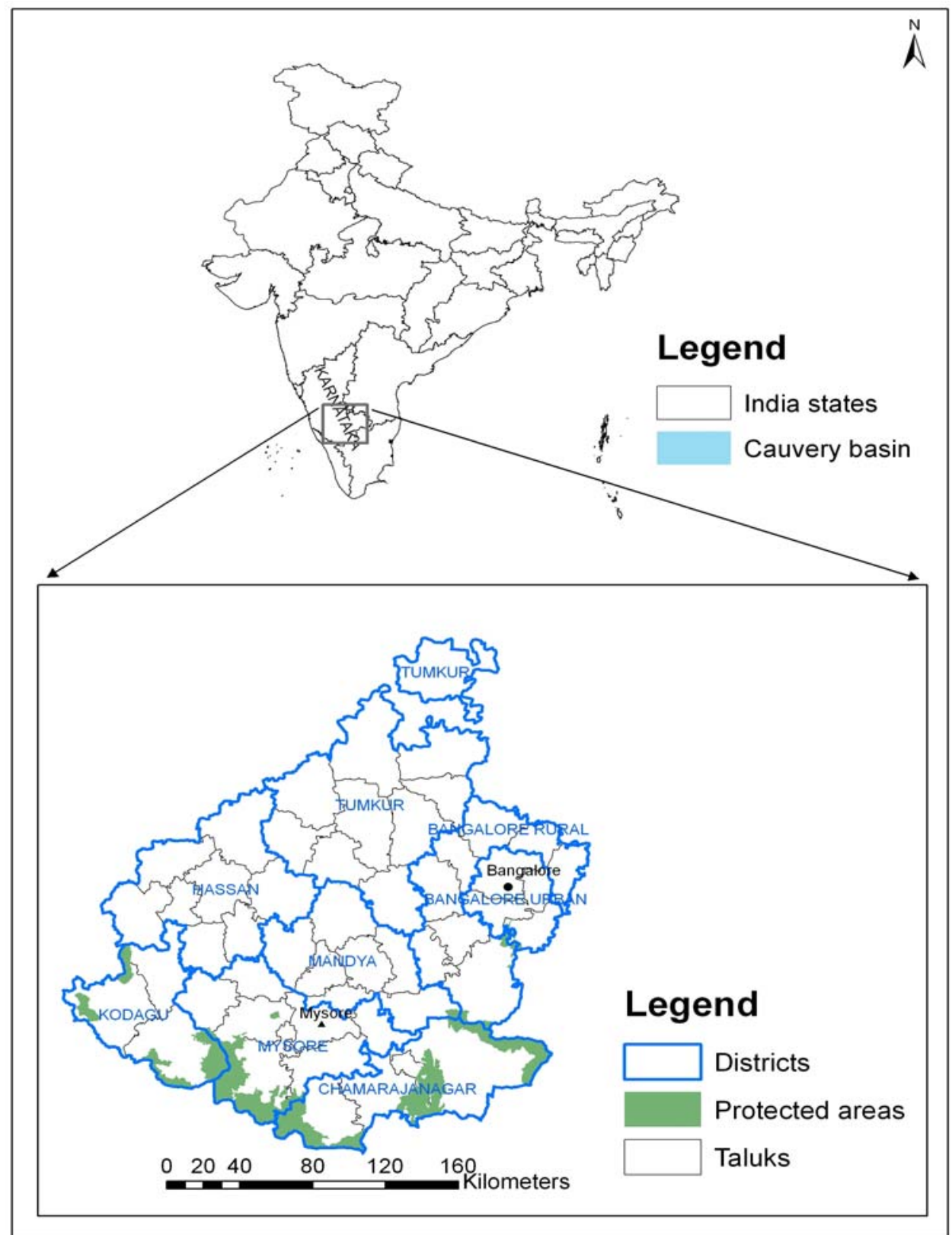

Figure 2 depicts the variation in elevation within this landscape. While districts like Kodagu are at very high elevations, with heterogeneous slopes, districts such as Mandya are on flat alluvial planes. 
Figure 2. Distribution of elevation in study area.

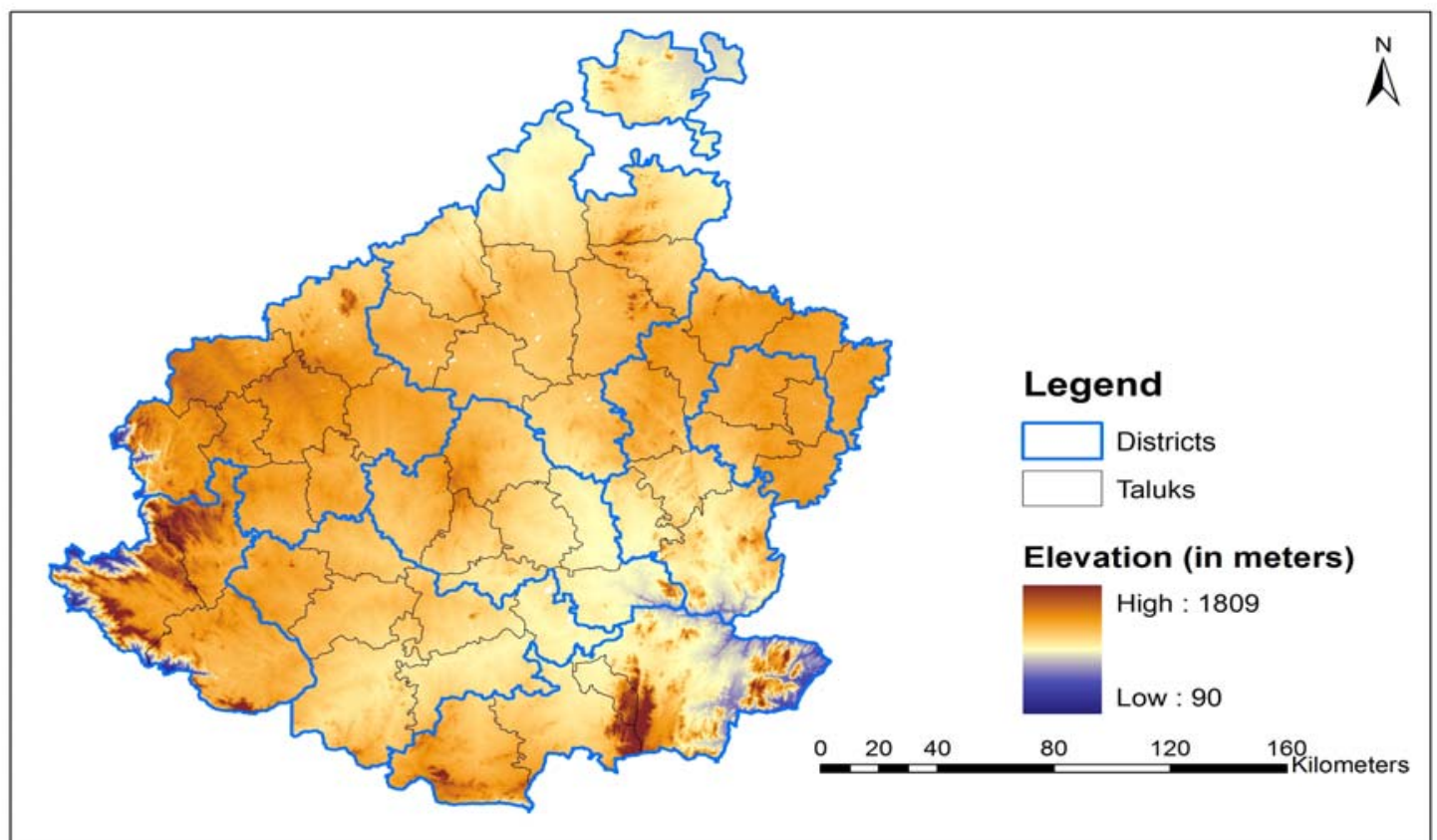

A visual comparison of Figure 4 with and Figures 1, 2, and 3 indicates stable forest is largely in the hilly south, in protected areas. The fertile central and northern plains are dominated by stable non-forest. Deforestation is greater in the hilly south-east and south-west and outside protected areas.

Figure 3. Population density distribution in study area.

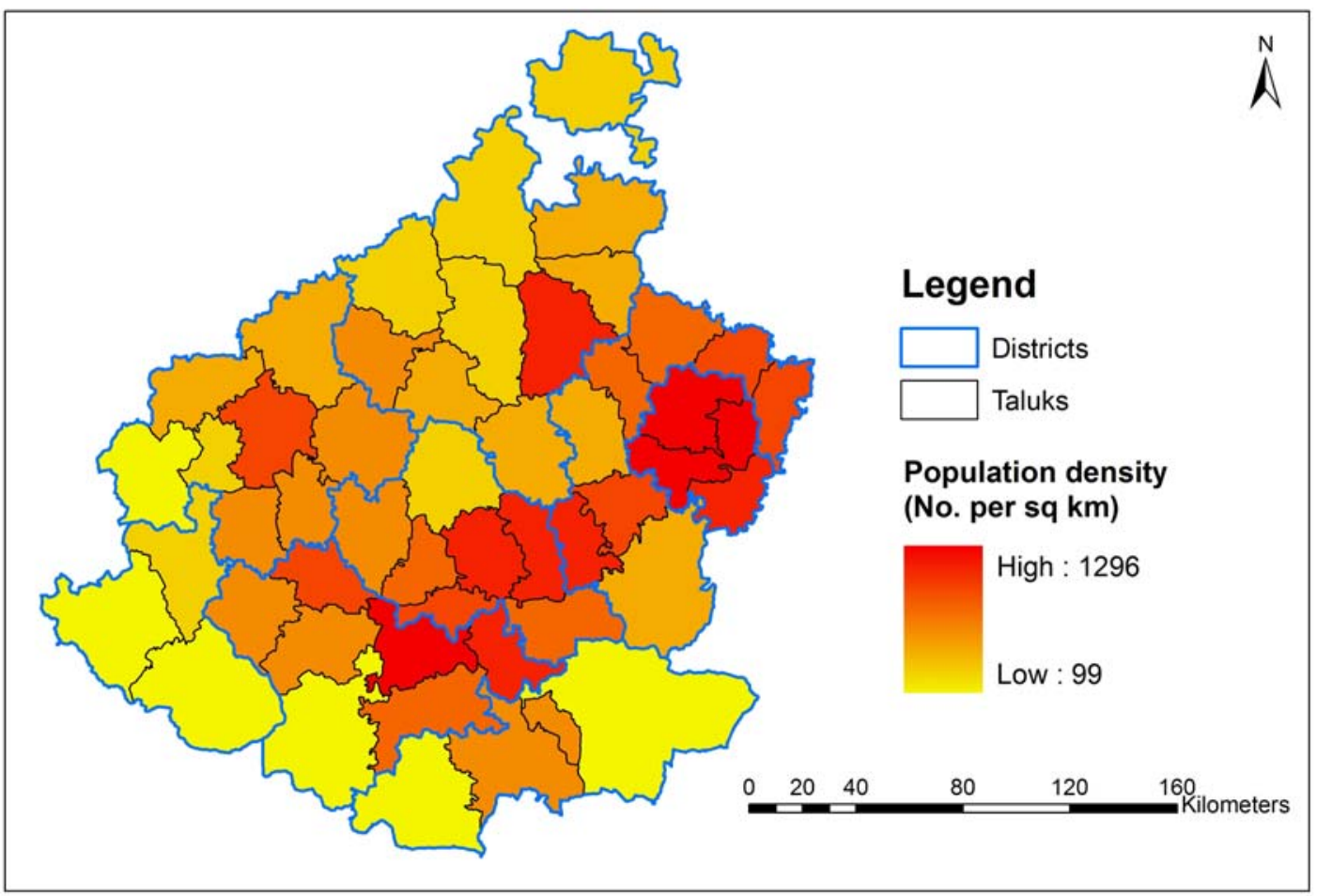


Figure 4. Map of forest change trajectories between 2001-2006.

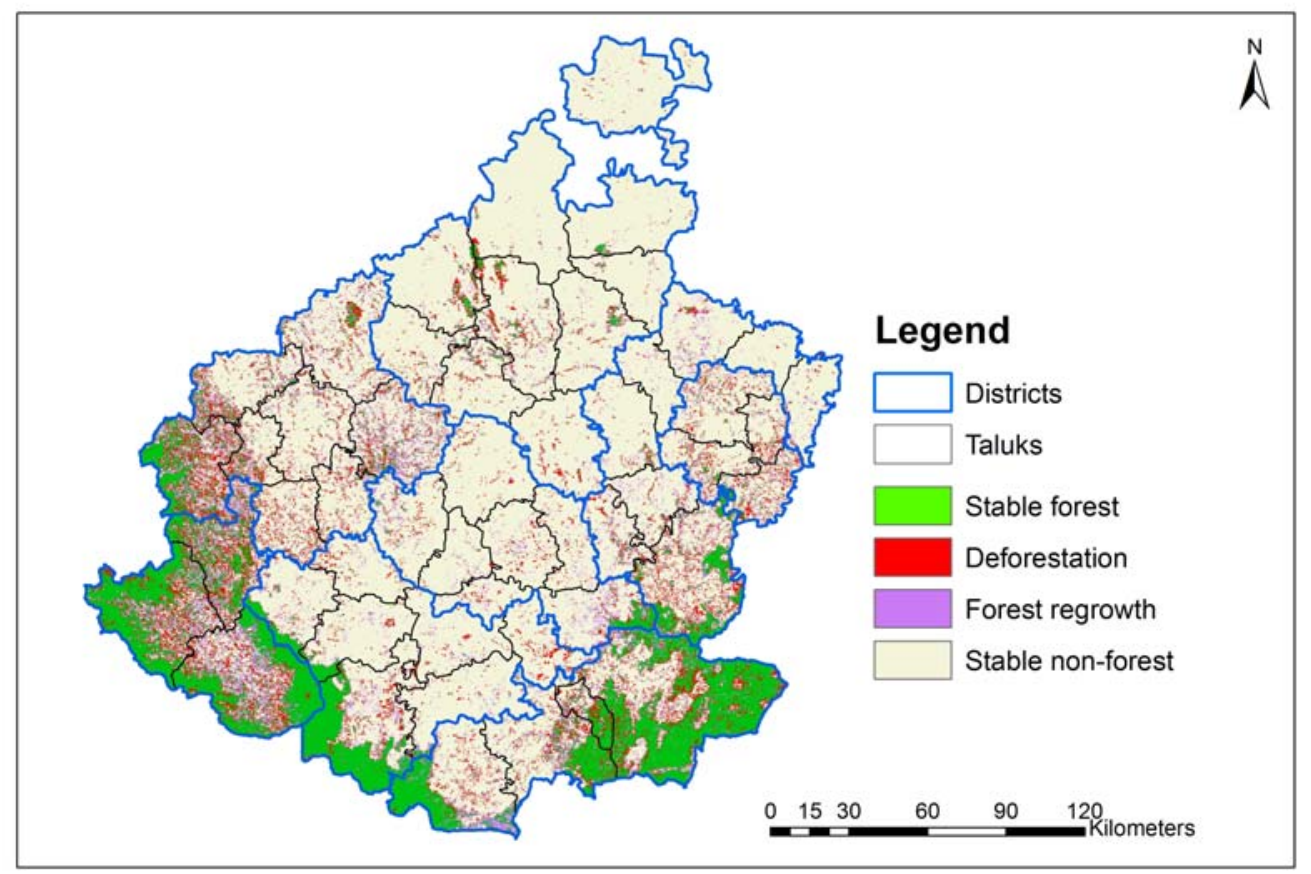

At the district scale and taluk scale, Pearson's correlation coefficients were calculated and linear regressions were conducted to determine the nature and significance of the dependence of forest change on population density, mean elevation, variation in elevation (measured as the standard deviation in elevation values for each district/taluk), and the percentage of area within protected areas (PAs). We focused on the stable forest and deforestation change trajectories, as this analysis focuses on understanding the drivers of forest clearing and stability. Correlations between independent variables of the regression were calculated to check for multicollinearity. At the district scale, standard deviation in elevation was significantly correlated with the percentage of area within PAs $(r=0.83$, $\mathrm{p}<0.01$ ), but no other significant correlations were observed between the four variables of mean elevation, standard deviation of elevation, population density, and \% area within PAs $(\alpha=0.05)$. At the taluk scale, there was a statistically significant correlation between standard deviation in elevation and population density $(\mathrm{r}=-0.34, \mathrm{p}<0.01)$, and between standard deviation in elevation and $\%$ area within PAs $(r=0.54, p<0.01)$, but no other significant correlations.

\subsection{Forest Change at the District and Taluk Scales}

\subsubsection{Impact of Population Density}

At the district scale, no significant relationships were found between population density and the distribution of stable forest (Figure $5 \mathrm{a}, \mathrm{r}^{2}=0.13, \mathrm{p}=0.38$ ). However, when one outlier district-representing the city of Bangalore, with a population density much greater than other districts-was removed from analysis, then population density was found to have a significant negative impact on the distribution of stable forest $\left(\mathrm{r}^{2}=0.52, \mathrm{p}<0.05\right)$. This is as expected, as when a region becomes more populated, pressures on land available for cultivation, settlement and other human uses could be expected to increase, resulting in a decrease in stable forest cover. 
Figure 5a. Relationship between population density and the distribution of stable forest for districts.

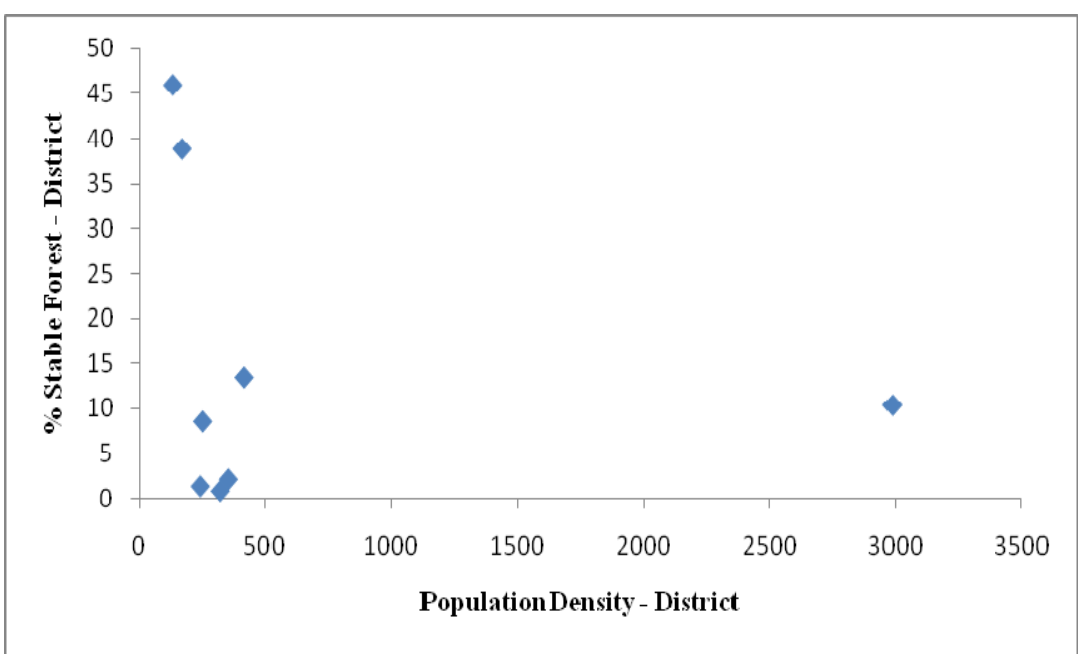

Similar trends are observed at the taluk scale (Figure 5b). Population density was not a significant predictor of stable forest $\left(\mathrm{r}^{2}=0.04, \mathrm{p}=0.17\right)$. Once data from three outlier taluks with very high values of population density greater than $1000 / \mathrm{km}^{2}$ (Bangalore Urban, Bangalore Rural and Mysore) were removed, this variable became a significant and stronger predictor of the distribution of stable forest $\left(\mathrm{r}^{2}=0.31, \mathrm{p}<0.01\right)$.

Figure 5b. Relationship between population density and the distribution of stable forest for taluks.

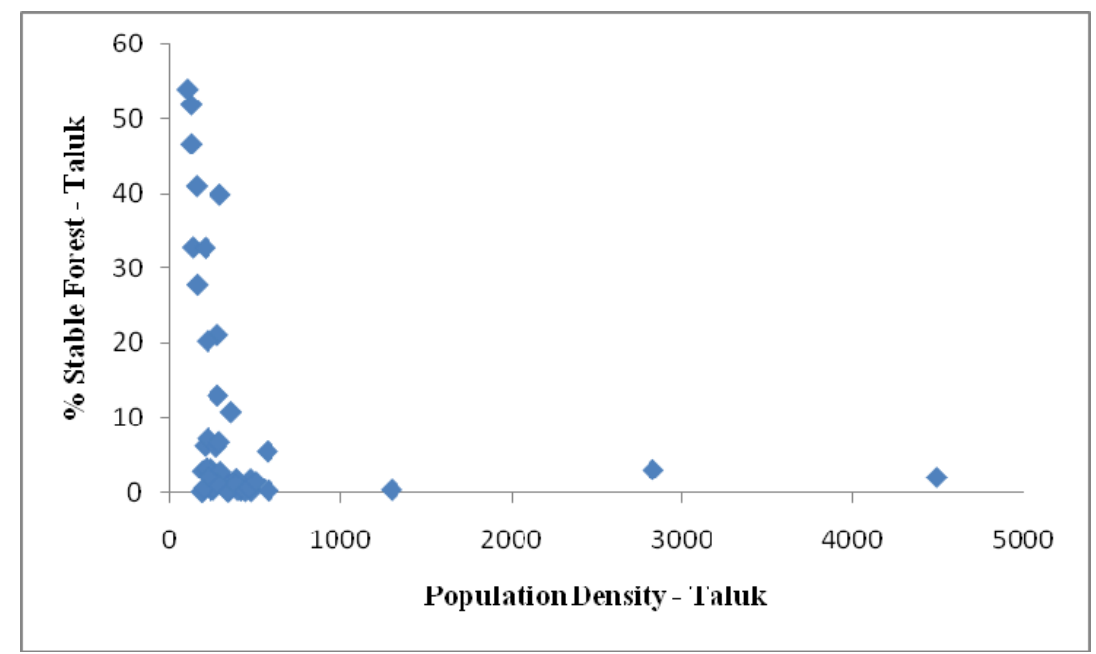

Population density was not a significant predictor of deforestation at the district scale (Figure 6a, $\left.\mathrm{r}^{2}=0.00001, \mathrm{p}=0.99\right)$. Somewhat counter-intuitively, though, when the outlier district of Bangalore was removed from analysis, it emerged as a significant negative predictor of deforestation $\left(\mathrm{r}^{2}=0.61\right.$, $\mathrm{p}<0.05)$. 
Figure 6a. Relationship between population density and the distribution of deforestation for districts.

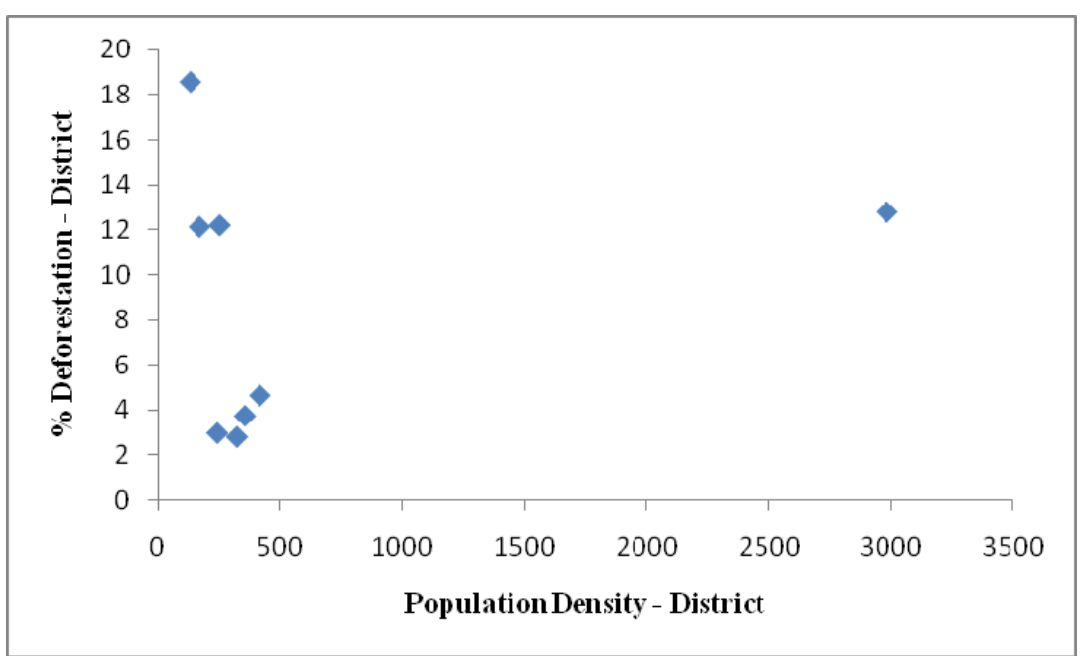

A similar trend was observed for taluks. While population density was not a significant predictor of deforestation (Figure $6 \mathrm{~b}, \mathrm{r}^{2}=0.001, \mathrm{p}=0.87$ ), when three outliers (Bangalore North, Bangalore South and Mysore) were removed, there was a weak, but significant negative impact $\left(r^{2}=0.11, p<0.05\right)$.

Figure 6b. Relationship between population density and the distribution of deforestation for taluks.

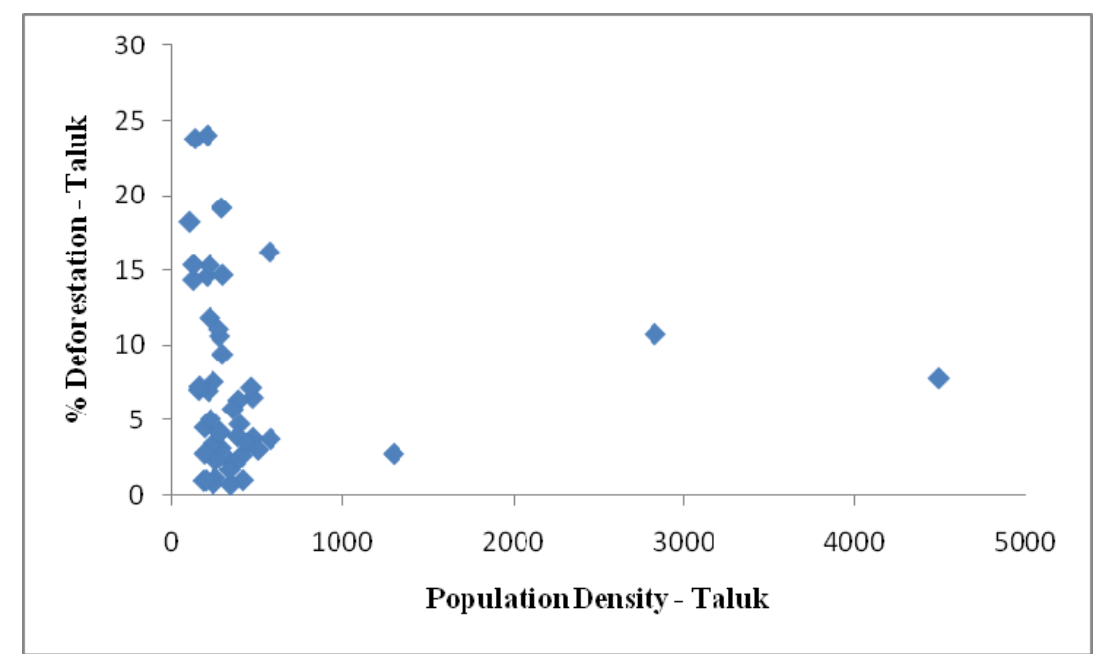

A possible explanation is that most of the forested land originally available for cultivation and settlement in the more populated districts has already been cleared by 2001 (as shown by the significant negative relationship between stable forest and population density). Thus, the availability of land for further clearing and human use is greater in the less populated, densely forested districts, which can explain the fact that these districts are now facing increased deforestation.

In order to evaluate this hypothesis, we calculated another estimate of the percentage of deforestation relative to the forest area existing in 2001. We then assessed the relationship between population density and this variable. At the district scale, population density was not a significant 
predictor of deforestation (Figure $7 \mathrm{a}, \mathrm{r}^{2}=0.01, \mathrm{p}=0.77$ ), and this did not change substantially when the outlier district of Bangalore was removed $\left(r^{2}=0.08, p=0.54\right)$.

Figure 7a. Relationship between population density and the distribution of deforestation as a percentage of the forest area existing in 2001, for districts.

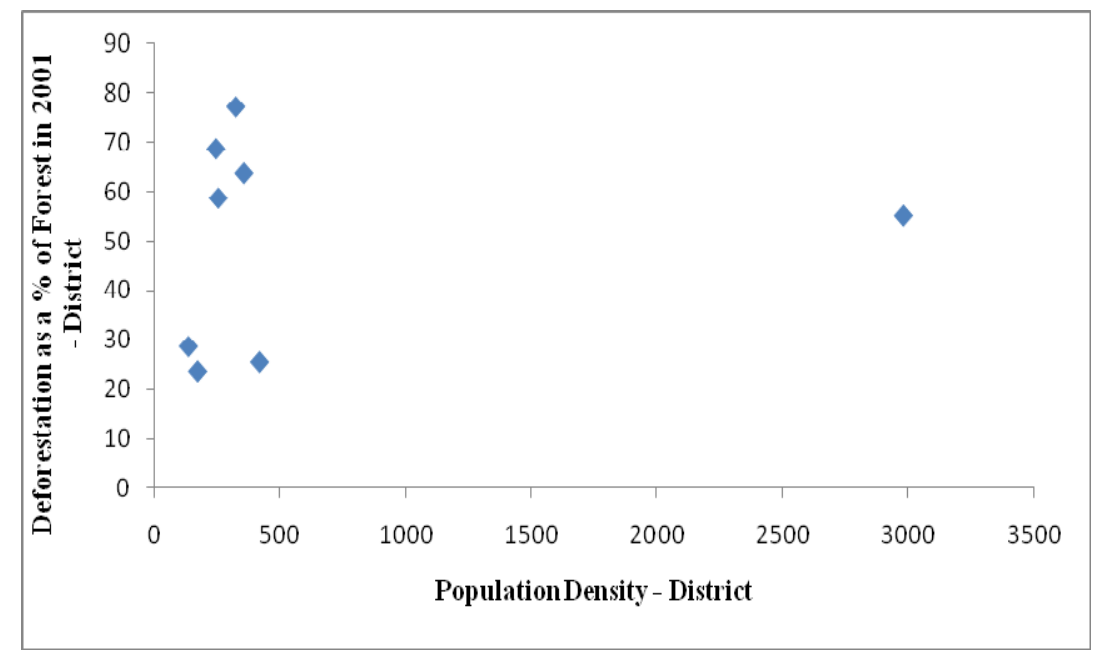

At the taluk scale, population density was not a significant predictor of deforestation as a percentage of the available forest cover in 2001 (Figure $7 b, r^{2}=0.05, p=0.11$ ). When the three outlier taluks were removed, however, there was a significant positive impact of population density on deforestation calculated as a percentage of the forested area existing in 2001 , as expected $\left(\mathrm{r}^{2}=0.31\right.$, $\mathrm{p}<0.001)$.

Figure 7b. Relationship between population density and the distribution of deforestation as a percentage of the forest area existing in 2001, for taluks.

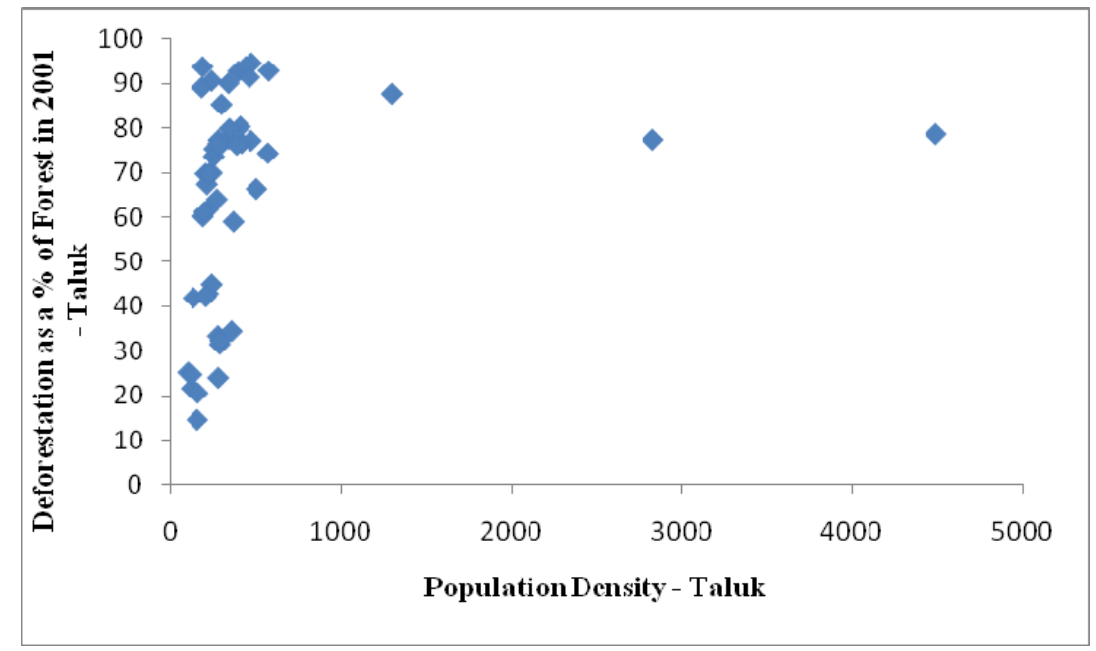

\subsubsection{Impact of Mean Elevation}

Mean elevation does not emerge as a significant predictor of the distribution of stable forest at the district scale (Figure 8a, $r^{2}=0.07, p=0.52$ ), or at the taluk scale (Figure 8b, $r^{2}=0.001, p=0.54$ ). 
Figure 8a. Relationship between mean elevation and the distribution of stable forest for districts.

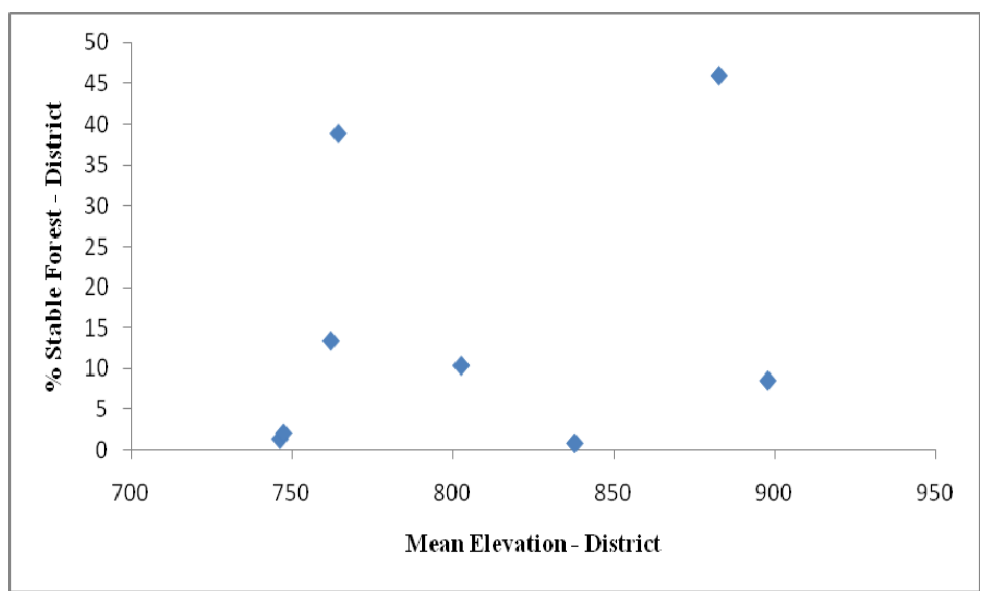

Figure 8b. Relationship between mean elevation and the distribution of stable forest for taluks.

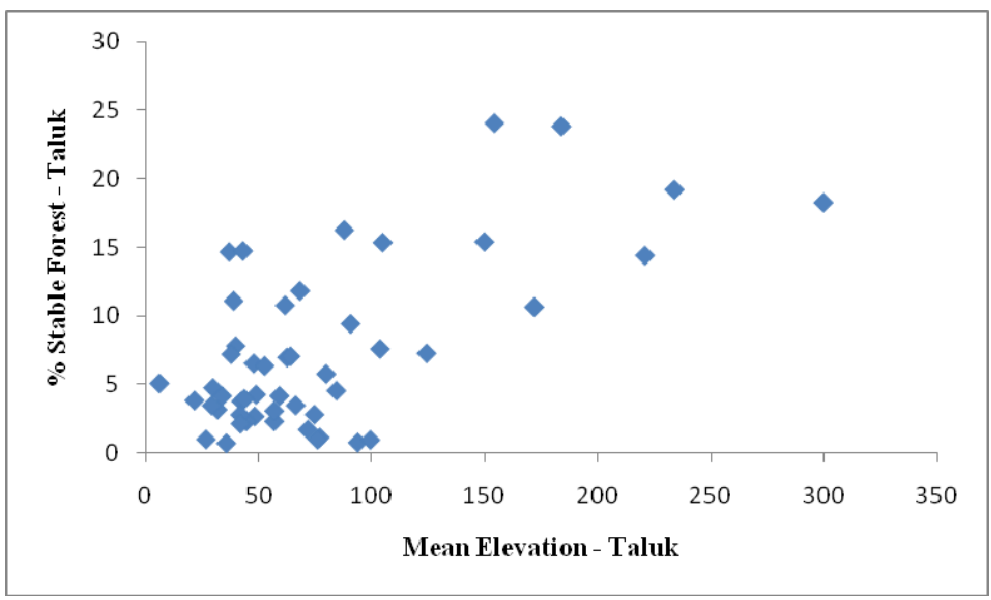

Mean elevation is not a significant driver of the distribution of deforestation at the district scale (Figure 9a, $\mathrm{r}^{2}=0.61, \mathrm{p}=0.1$ ).

Figure 9a. Relationship between mean elevation and the distribution of deforestation for districts.

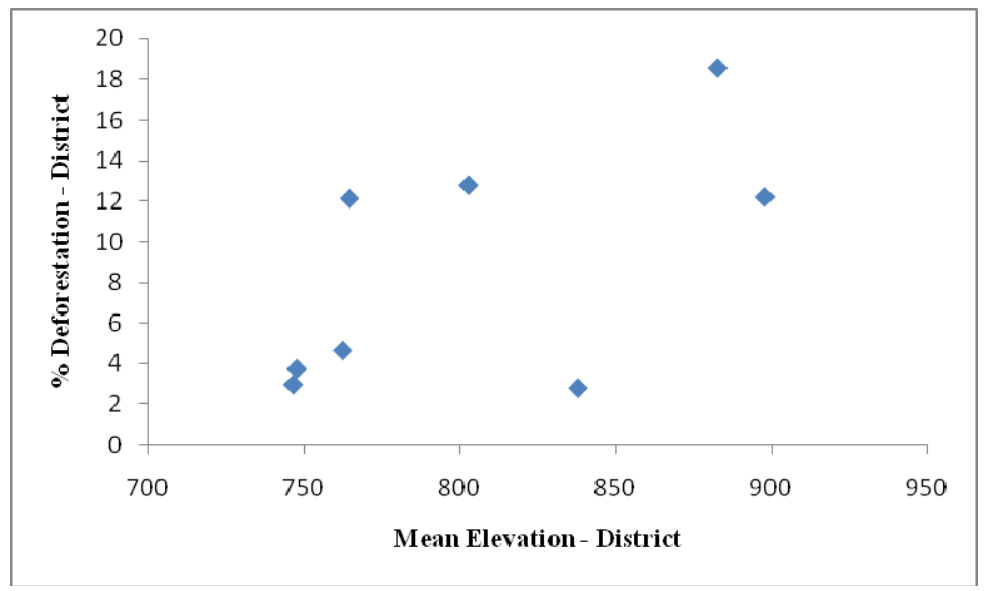


At the taluk scale, however, mean elevation is a significant and negative, though weak predictor of deforestation (Figure 9b, $\mathrm{r}^{2}=0.13, \mathrm{p}<0.01$ ).

Figure 9b. Relationship between mean elevation and the distribution of deforestation for taluks.

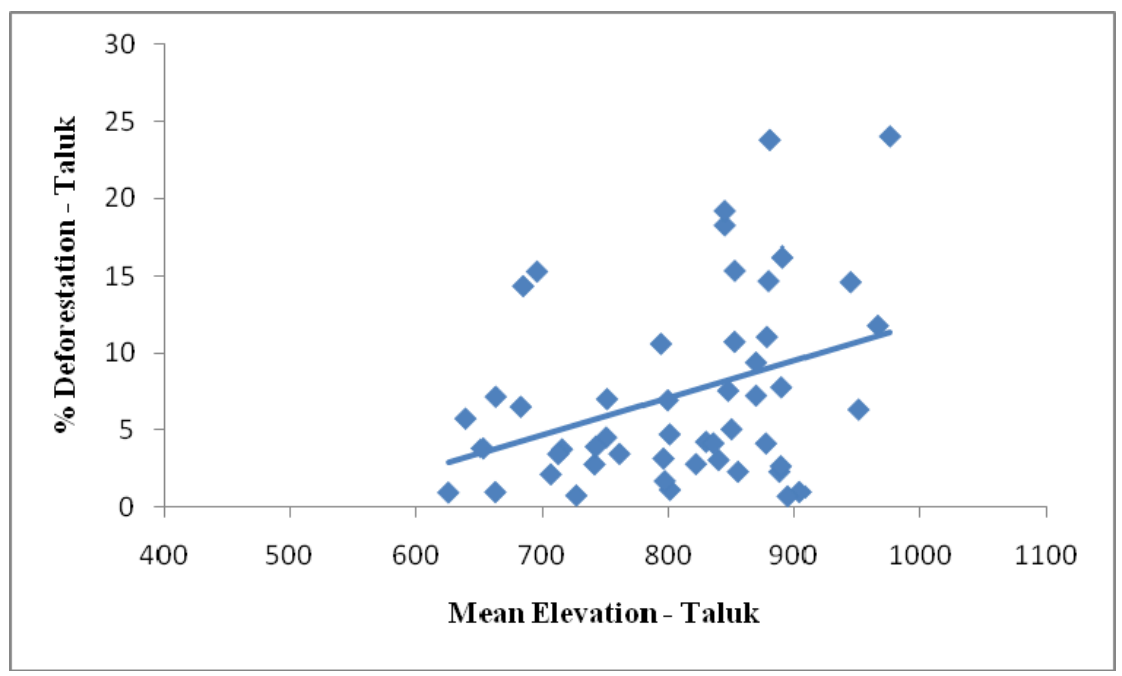

Like the positive association between deforestation and population density, this is somewhat counter-intuitive. The likely explanation, again, is that most of the forested land originally available for cultivation and settlement at low elevations has already been cleared of forest cover by 2001 (as can also be seen from a visual comparison of Figure 2 and Figure 4). As forest timber and land are now only available in the hilly taluks, most clearing between 2001-2006 appears to be taking place in these areas. This premise was evaluated by assessing the relationship between mean elevation, and an estimate of the percentage of deforestation relative to the forest area existing in 2001. Mean elevation was not a significant predictor of deforestation at the district scale (Figure 10a, $\mathrm{r}^{2}=0.001, \mathrm{p}=0.95$ ) or the taluk scale (Figure $10 \mathrm{~b}, \mathrm{r}^{2}=0.004, \mathrm{p}=0.66$ ). This affirms our premise that mean elevation does not directly impact deforestation, although it may have a weak indirect influence by impacting the distribution of forest cover available for further clearing.

Figure 10a. Relationship between mean elevation and the distribution of deforestation as a percentage of the forest area existing in 2001, for districts.

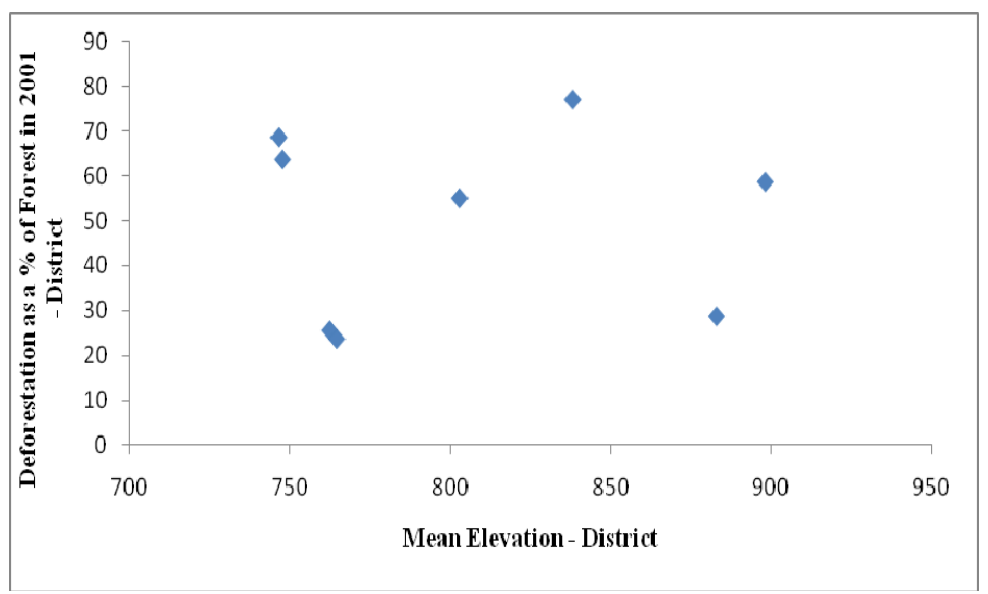


Figure 10b. Relationship between mean elevation and the distribution of deforestation as a percentage of the forest area existing in 2001, for districts.

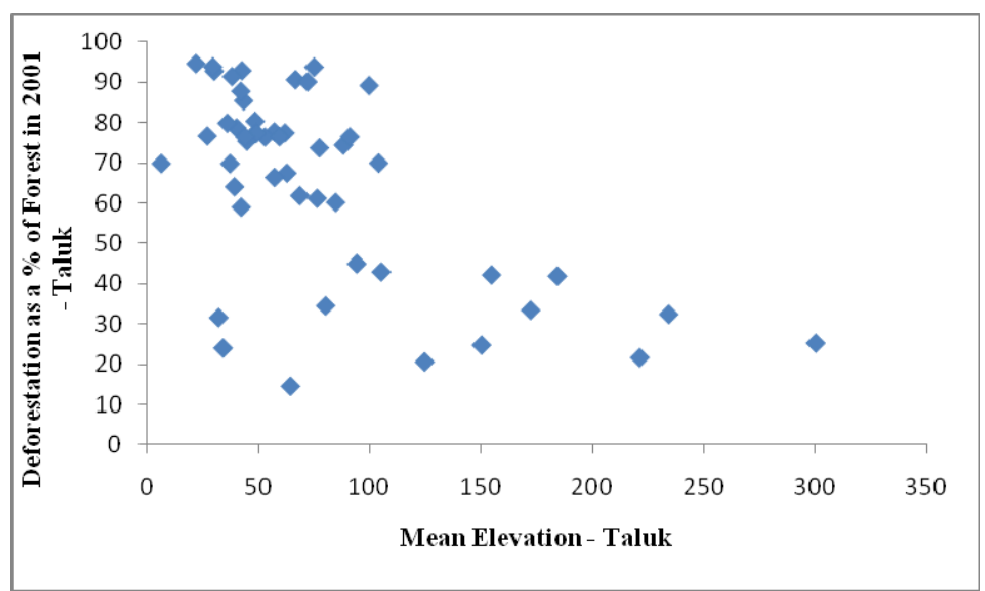

\subsubsection{Impact of Variation in Elevation}

The variation in elevation or heterogeneity of terrain (as measured by the standard deviation in elevation) in districts and taluks provides another indication of landscape accessibility, which is not correlated with mean elevation for this dataset. Variation in elevation is a significant, strong positive driver of the distribution of stable forest at the district scale (Figure 11a, $\mathrm{r}^{2}=0.87, \mathrm{p}<0.01$ ) and at the taluk scale (Figure $11 \mathrm{~b}, \mathrm{r}^{2}=0.69, \mathrm{p}<0.01$ ). As may have been expected, most of the stable forest in this landscape appears to be located in regions of heterogeneous terrain, which are difficult to access.

Figure 11a. Relationship between variation in elevation and the distribution of stable forest for districts.

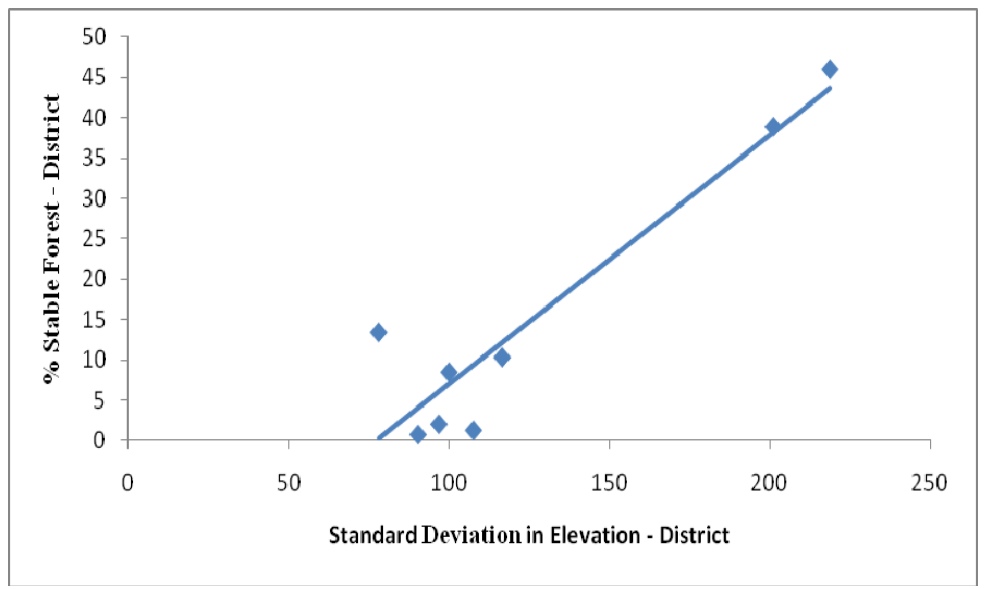


Figure 11b. Relationship between variation in elevation and the distribution of stable forest for taluks.

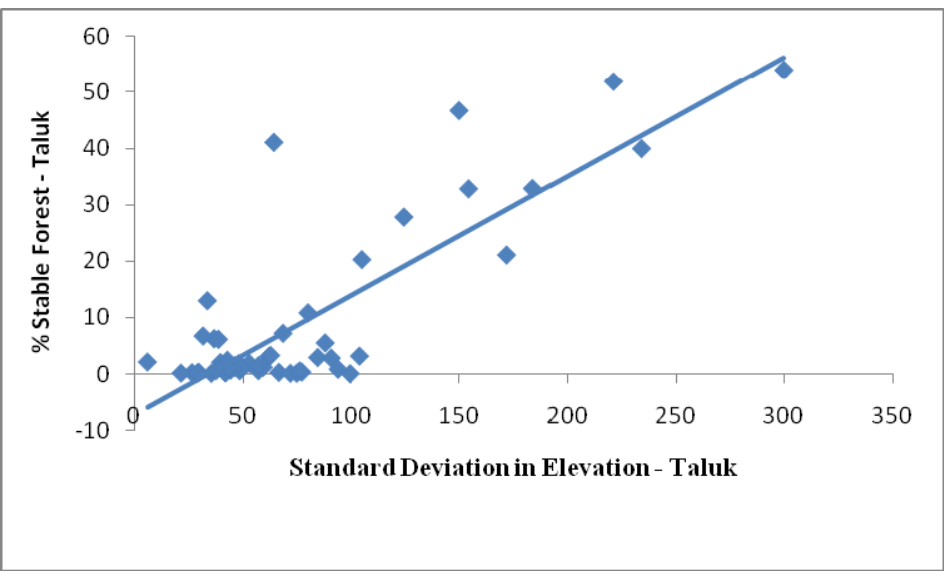

Variability in elevation is also significantly and positively associated with the distribution of deforestation at the district level (Figure 12a, $\mathrm{r}^{2}=0.59, \mathrm{p}<0.05$ ), and the taluk level (Figure 12b, $\left.r^{2}=0.43, p<0.01\right)$, although not as strongly as the association with the distribution of stable forest.

Figure 12a. Relationship between variation in elevation and the distribution of deforestation for districts.

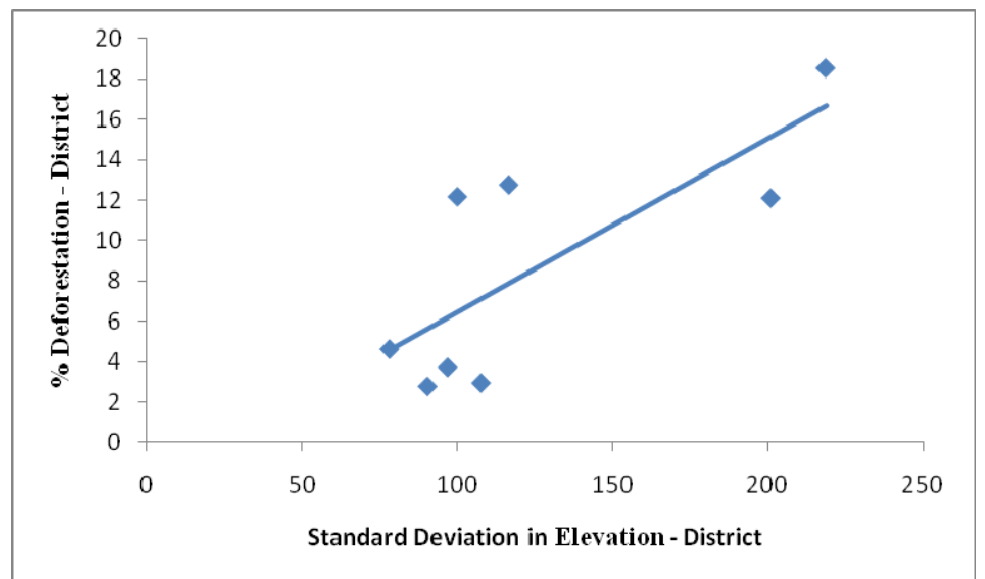

Figure 12b. Relationship between variation in elevation and the distribution of deforestation for taluks.

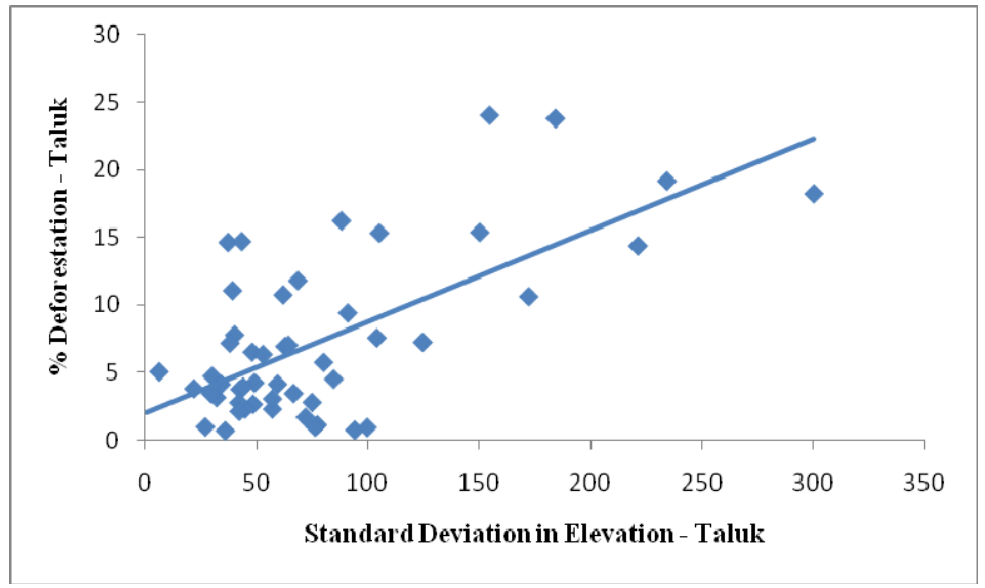


The fact that increased variability in elevation leads to an increase in deforestation is puzzling, and also appears to relate to the availability of forest land for harvest of timber and land clearing, as observed with population density and mean elevation. That is, the availability of land for further forest clearing is low in the districts with relatively homogeneous elevation. This assumption was also evaluated by assessing the relationship between mean elevation, and an estimate of the percentage of deforestation relative to the forest area existing in 2001. Variability in elevation was not a significant predictor of deforestation at the district scale (Figure $13 \mathrm{a}, \mathrm{r}^{2}=0.37, \mathrm{p}=0.11$ ). At the taluk scale, however, variability in elevation was significantly, but negatively associated with deforestation as a percentage of the forest area in 2001 (Figure 13b, $\mathrm{r}^{2}=0.43, \mathrm{p}<0.001$ ). This variable shows some heteroskedasticity, with greater variation in the proportion of deforestation at lower levels of variability in elevation. This heteroskedasticity did not follow standard forms and could not be corrected by standard transformations of the independent variable, or by other commonly used approaches. The existence of heteroskedasticity will not affect regression estimates, but it does caution us of chances of overestimating the significance of this relationship. In conclusion, the relationship between variability in elevation and the distribution of deforestation appears complex. Variability in elevation indirectly increases the likelihood of deforestation, as areas with greater variability in elevation have more forested area available for further clearing (Figure 12b). Once this is taken into account, however, areas with greater variability in elevation may have a decreased likelihood of deforestation occurring (Figure 13b).

Figure 13a. Relationship between variation in elevation and the distribution of deforestation as a percentage of the forest area existing in 2001, for districts.

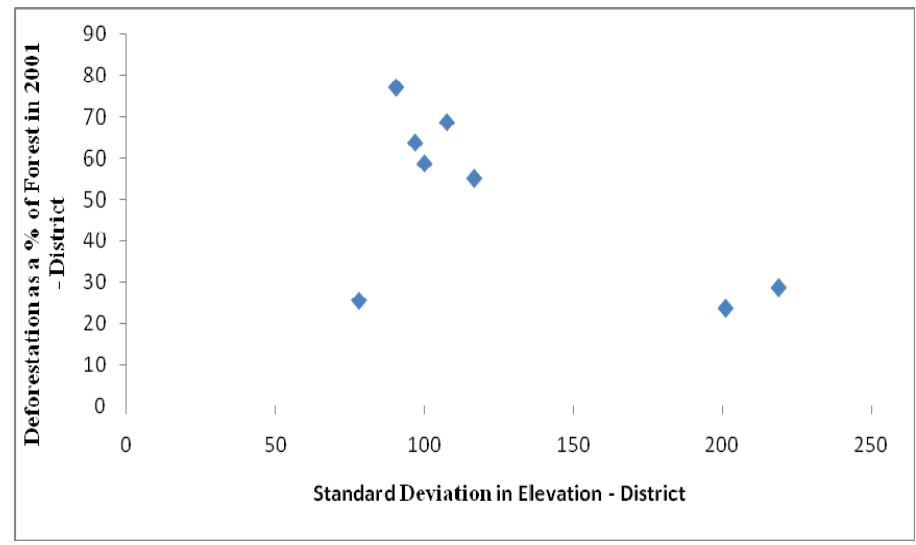

Figure 13b. Relationship between variation in elevation and the distribution of deforestation as a percentage of the forest area existing in 2001 , for taluks.

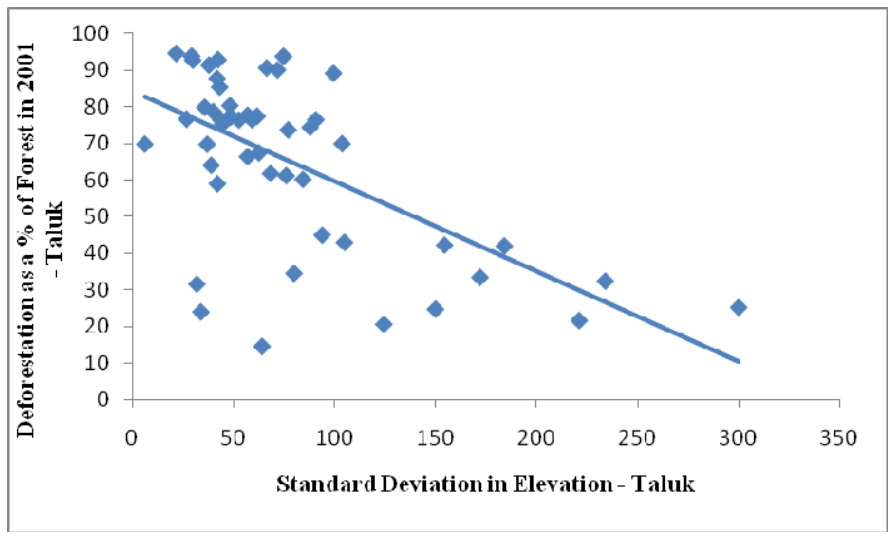




\subsubsection{Impact of Protected Areas}

The percentage of area located within PAs is a strong and positive predictor of the distribution of stable forest both at the district scale (Figure $14 \mathrm{a}, \mathrm{r}^{2}=0.80, \mathrm{p}<0.01$ ) and the taluk scale (Figure $14 \mathrm{~b}$, $\left.\mathrm{r}^{2}=0.63, \mathrm{p}<0.01\right)$. Clearly therefore, protected areas has been very effective in conserving stable forest cover in this region.

Figure 14a. Relationship between percentage of area within PAs and the distribution of stable forest for districts.

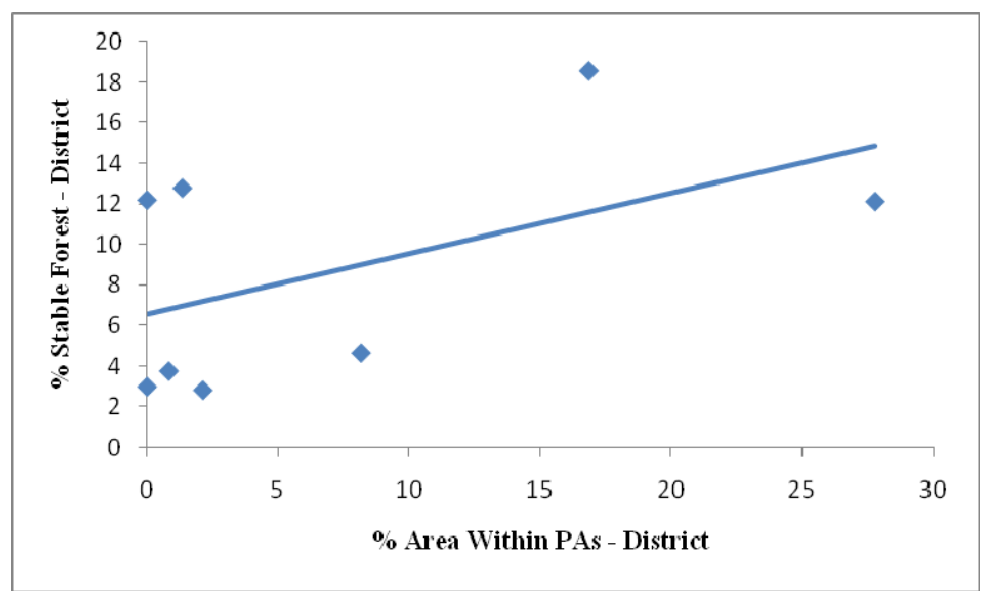

Figure 14b. Relationship between percentage of area within PAs and the distribution of stable forest for taluks.

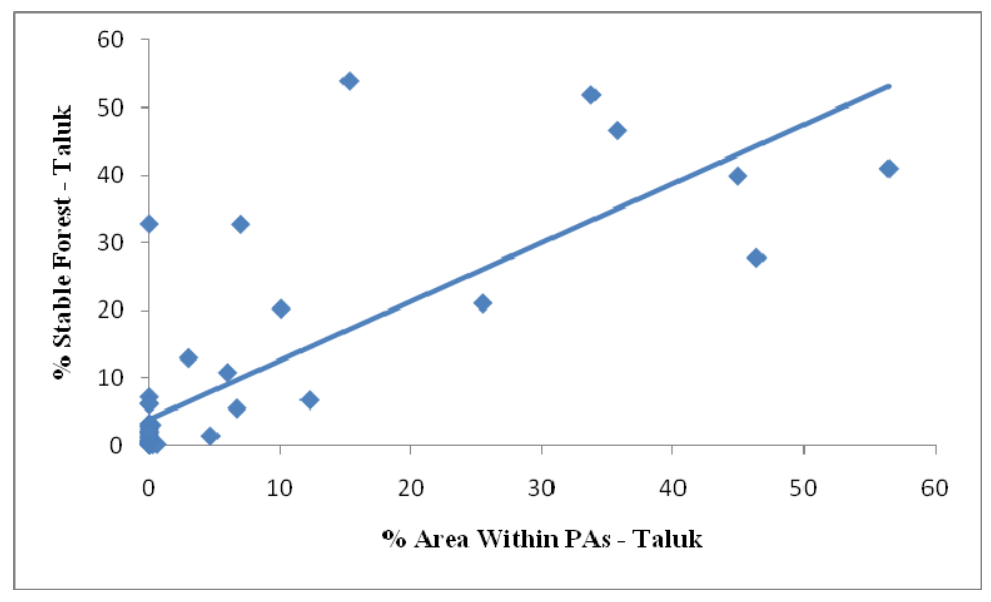

The percentage of area located within PAs does not however appear to have a significant impact on deforestation at the district scale (Figure $15 \mathrm{a}, \mathrm{r}^{2}=0.26, \mathrm{p}=0.19$ ), although it does emerge as a significant and positive, though weak predictor of deforestation at the taluk scale (Figure 15b, $\left.\mathrm{r}^{2}=0.13, \mathrm{p}<0.05\right)$. This variable also shows some heteroskedasticity at the taluk scale, which did not follow standard forms and could not corrected by standard transformations of the independent variable, or by other commonly used approaches. While this will not affect regression estimates, it cautions us of chances of overestimating the significance of this relationship, especially in this instance when the regression coefficient and the level of significance are both fairly low. This appears to indicate that, despite (or because of) the fact that a significant proportion of stable forest is located within PAs, these 
areas appear to be having at best a very limited impact on reducing deforestation within their boundaries, facing some degree of human pressure and requiring better management.

Figure 15a. Relationship between percentage of area within PAs and the distribution of deforestation for districts.

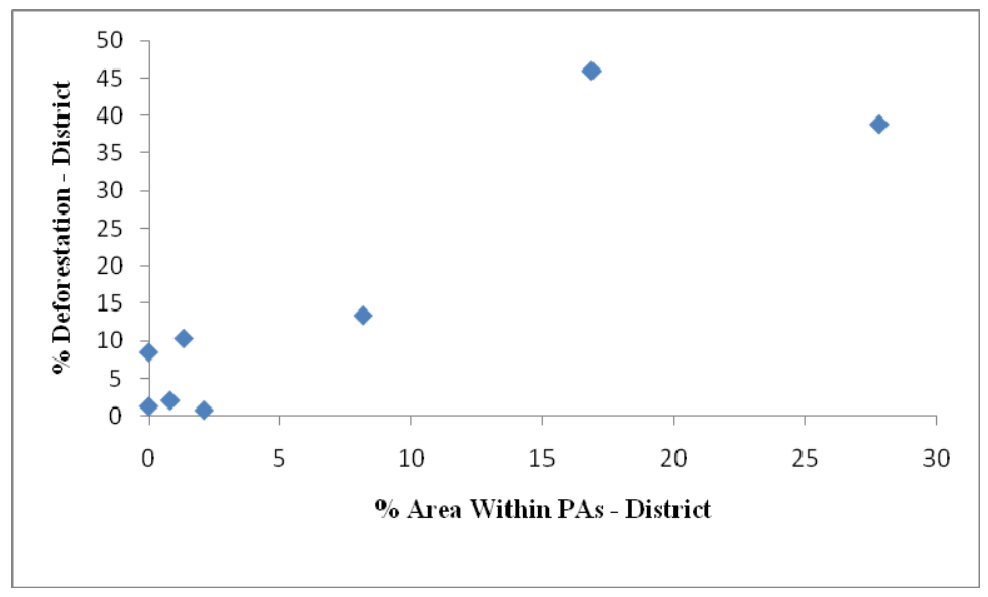

Figure 15b. Relationship between percentage of area within PAs and the distribution of deforestation for taluks.

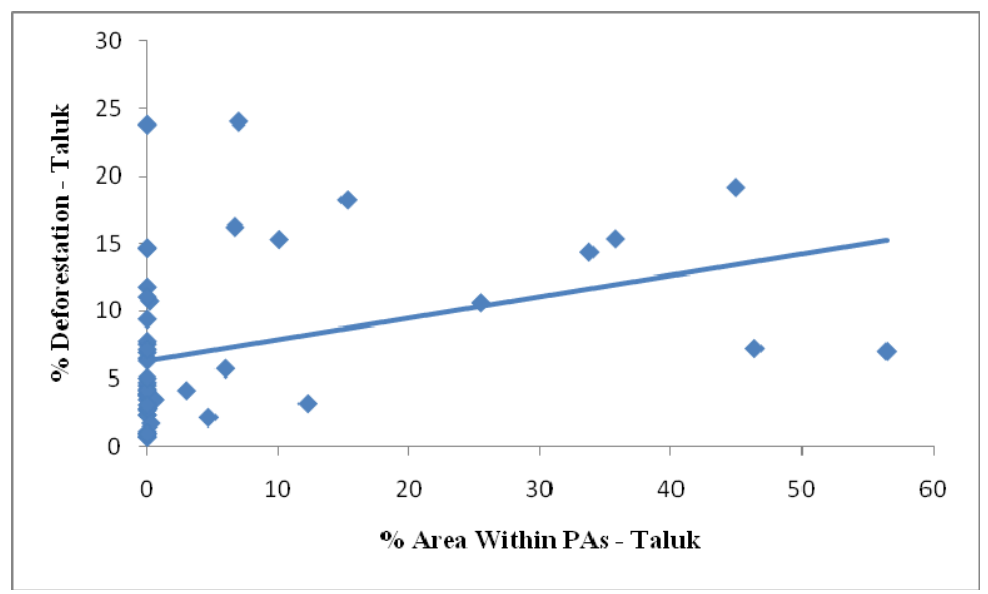

When the availability of forest cover for further change is taken into account, however, by assessing deforestation as a percentage of the forest area existing in 2001, the percentage of area located within PAs emerges as a significant and weak but negative predictor of deforestation at the district scale (Figure $16 \mathrm{a}, \mathrm{r}^{2}=0.66, \mathrm{p}<0.05$ ), and at the taluk scale (Figure $16 \mathrm{~b}, \mathrm{r}^{2}=0.13, \mathrm{p}<0.05$ ). This variable also shows some heteroskedasticity at the taluk scale, which did not follow standard forms and could not be corrected by standard transformations of the independent variable, or by other commonly-used approaches. While this will not affect regression estimates, it cautions us of chances of overestimating the significance of this relationship, especially in this instance when the regression coefficient and the level of significance are both fairly low. This however reinforces our conclusion that PAs in this landscape have been successful in maintaining stable forest cover and reducing deforestation. 
Figure 16a. Relationship between percentage of area within PAs and the distribution of deforestation as a percentage of the forest area existing in 2001, for districts.

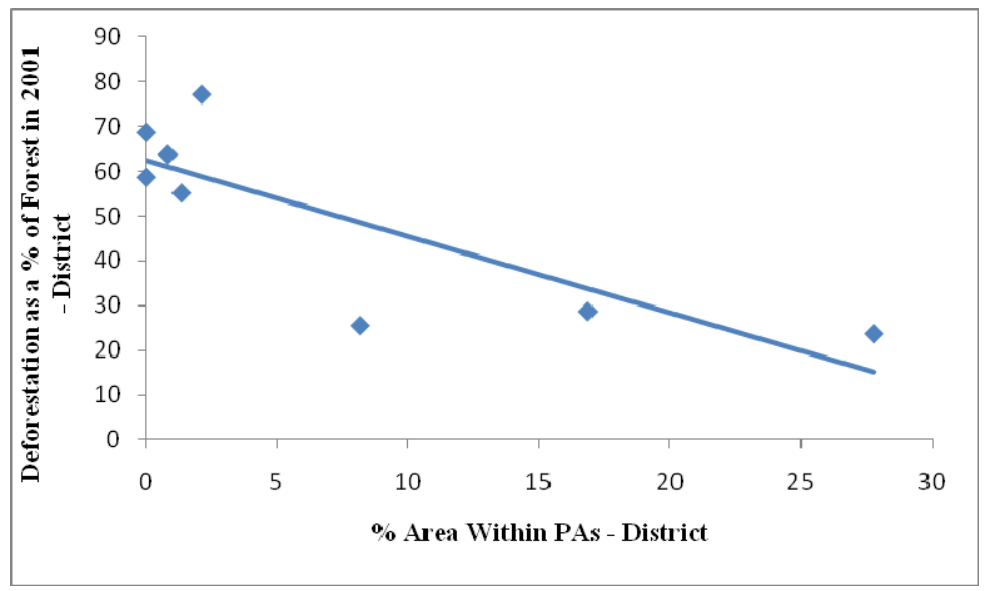

Figure 16b. Relationship between percentage of area within PAs and the distribution of deforestation as a percentage of the forest area existing in 2001, for taluks.

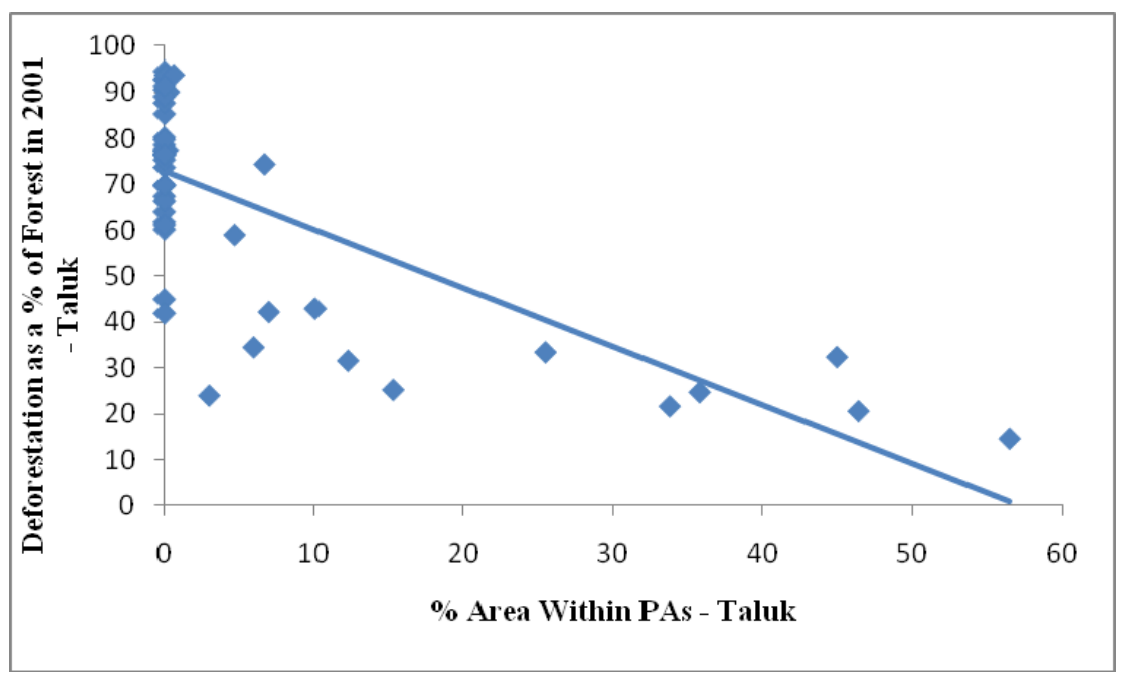

\subsubsection{Impact of All Variables}

In addition to considering these variables separately, the combined impact of these variables was assessed using a multiple regression analysis [39]. For all models, variance inflation factors were less than 2 for all independent variables, indicating that multicollinearity between variables was not significant. At the district scale, the major drivers of the distribution of stable forest is the $\%$ of area within PAs, followed by variation in elevation - neither of these is significant (at $p<0.05)$ however, possibly because of the low sample size involved (Table 1). At the taluk scale, variation in elevation is the most significant variable, followed by \% of area within PAs (Table 1). Both of these coefficients are significant at $\mathrm{p}<0.01$. Mean elevation, not a significant predictor of the distribution of stable forest when taken individually, is as expected not significant when taken in conjunction with other variables either. Interestingly, once variation in elevation and the $\%$ of area within PAs are taken into account, population density - which was a significant negative predictor of stable forest cover when taken individually-loses its significance. For the multiple regression, these values do not change 
substantially when the outlier district of Bangalore, or the three outlier taluks of Bangalore North, Bangalore South and Mysore with high population density are removed, providing another indication that population does not have a major role to play on its own in driving the distribution of stable forest cover in this landscape.

Table 1. Nature, strength and significance of four proposed drivers of forest change-population density, average elevation, variation in elevation and percentage within PAs - on the distribution of stable forest in the study region, at the scale of districts and taluks. Results based on a linear multiple regression analysis. Significance codes: $* * \mathrm{p}<0.01, * \mathrm{p}<0.05$.

\begin{tabular}{|c|c|c|c|c|c|c|c|}
\hline \multirow[b]{2}{*}{$\begin{array}{l}\text { Spatial } \\
\text { scale }\end{array}$} & \multirow[b]{2}{*}{$\begin{array}{l}\text { Sample } \\
\text { size }\end{array}$} & \multirow[b]{2}{*}{$\mathbf{R}^{2}$} & \multirow[b]{2}{*}{$\begin{array}{c}\text { Intercep } \\
\mathbf{t}\end{array}$} & \multicolumn{4}{|c|}{ Slope } \\
\hline & & & & $\begin{array}{c}\text { Population } \\
\text { density }\end{array}$ & $\begin{array}{c}\text { Mean } \\
\text { elevation }\end{array}$ & $\begin{array}{c}\text { Variation in } \\
\text { elevation }\end{array}$ & $\begin{array}{c}\text { \% area within } \\
\text { PAs } \\
\end{array}$ \\
\hline & 8 & 0.946 & & 0.06 & 0.19 & 0.44 & 0.55 \\
\hline Taluks & 51 & 0.858 & -16.31 & -0.01 & 0.08 & $0.56^{* *}$ & $0.49 * *$ \\
\hline
\end{tabular}

The major driver of distribution of deforestation is the variation in elevation, followed by mean elevation, and finally by population density (Table 2). None of these variables are significant predictors of variation in deforestation at the district scale, however, possibly because of the low sample size involved. At the taluk scale as well, variation in elevation is the most significant variable, followed by mean elevation (Table 2). Both of these coefficients are significant at $p<0.01$. The $\%$ of area within PAs did not emerge as a significant predictor of the distribution of deforestation when taken individually, and is not a significant driver when taken in conjunction with other variables either. Once again, when variation in elevation and mean elevation are taken into account, population density, which was a significant negative predictor of deforestation when taken individually, loses its significance. As with the regression model for the distribution of stable forest, these values do not change substantially when the outlier district and taluks with high population density are removed, substantiating that population does not have a major role to play on its own in driving the distribution of deforestation in this landscape.

Table 2. Nature, strength and significance of four proposed drivers of forest change-population density, average elevation, variation in elevation and percentage within PAs - on the distribution of deforestation in the study region, at the scale of districts and taluks. Results based on a linear regression analysis. Significance codes: $* * p<0.01$, $* \mathrm{p}<0.05$.

\begin{tabular}{|c|c|c|c|c|c|c|c|}
\hline \multirow[b]{2}{*}{$\begin{array}{l}\text { Land cover } \\
\text { change } \\
\text { category }\end{array}$} & \multirow[b]{2}{*}{$\begin{array}{l}\text { Sample } \\
\text { size }\end{array}$} & \multirow[b]{2}{*}{$\mathbf{R}^{2}$} & \multirow[b]{2}{*}{ Intercept } & \multicolumn{4}{|c|}{ Slope } \\
\hline & & & & $\begin{array}{c}\text { Population } \\
\text { density }\end{array}$ & $\begin{array}{c}\text { Mean } \\
\text { elevatio } \\
\mathbf{n}\end{array}$ & $\begin{array}{c}\text { Variation } \\
\text { in elevation }\end{array}$ & $\begin{array}{c}\% \text { area } \\
\text { within PAs }\end{array}$ \\
\hline Districts & 8 & 0.902 & -44.21 & 0.36 & 0.49 & 0.59 & 0.14 \\
\hline Taluks & 51 & 0.545 & -16.170 & 0.08 & $0.33 * *$ & $0.64 * *$ & 0.03 \\
\hline
\end{tabular}


When assessing the distribution of deforestation as a percentage of the forest cover available in 2001 for further conversion, none of these variables emerge as significant predictors at the district scale, however, which is likely to be because of the low sample size (Table 3). At the taluk scale, the percentage within PAs emerges as the most significant variable $(\mathrm{p}<0.01)$, followed by variation in elevation $(p<0.05)$. Both of these emerge as negative predictors of deforestation once the area of forest available in 2001 is taken into account, indicating that the availability of forested area for further conversion significantly impacts the influence of other drivers of change in this long settled landscape. Population density is not a significant driver of deforestation in this landscape, and as with the regression model for the distribution of stable forest, the regression does not change substantially when the outlier district and taluks with high population density are removed.

Table 3. Nature, strength and significance of four proposed drivers of forest change-population density, average elevation, variation in elevation and percentage within PAs - on the distribution of deforestation as a percentage of the forest cover in 2001, at the scale of districts and taluks. Results based on a linear multiple regression analysis. Significance codes: $* * \mathrm{p}<0.01, * \mathrm{p}<0.05$.

\begin{tabular}{|c|c|c|c|c|c|c|c|}
\hline \multirow{2}{*}{$\begin{array}{l}\text { Spatial } \\
\text { scale }\end{array}$} & \multirow{2}{*}{$\begin{array}{l}\text { Sample } \\
\text { size }\end{array}$} & \multirow[b]{2}{*}{$\mathbf{R}^{2}$} & \multirow{2}{*}{$\begin{array}{l}\text { Intercep } \\
\mathbf{t}\end{array}$} & \multicolumn{4}{|l|}{ Slope } \\
\hline & & & & $\begin{array}{l}\text { Population } \\
\text { density }\end{array}$ & $\begin{array}{l}\text { Mean } \\
\text { elevation }\end{array}$ & $\begin{array}{l}\text { Variation } \\
\text { in elevation }\end{array}$ & $\begin{array}{l}\% \text { area } \\
\text { within PAs }\end{array}$ \\
\hline Districts & 8 & 0.706 & 81.61 & -0.16 & -0.11 & 0.35 & -1.16 \\
\hline Taluks & 51 & 0.620 & 95.55 & 0.09 & -0.08 & $-0.28 *$ & $-0.57 * *$ \\
\hline
\end{tabular}

\section{Conclusions}

The drivers of forest change are complex, varying with context and with spatial scale. Thus, in order to accurately model and understand the drivers of land cover change we need to study landscape change across large regions with variations in local context, as well as at multiple spatial scales. As such, the approach we use in this research is important to allow for a regional representation of drivers of forest change and to understand their variation with local context, as well to verify such drivers across scales and thus better understand the system under study. Within our analysis we looked at the main identified drivers of deforestation in the literature: population, protection and accessibility [1,4-13]. Our results were sometimes seemingly counterintuitive, but as a consequence, provide important information about the drivers of forest change in settled landscapes. In order to predict changes in forest cover, the capacity of the landscape to support further change must be taken into account. In this landscape, which represents an area that has been long settled and used by humans, in areas with high population density and landscape accessibility without any protected areas, the useable agricultural areas are already in use, and as such it appears that additional deforestation is simply not feasible. As a consequence, areas of clearing are now observed in regions previously left forested because of their challenging topography, which is unexpected - until one takes into account the fact that most accessible areas have been previously cleared of forest cover, so that options for further deforestation are limited, as we find when we repeat our analysis by estimating deforestation as a percentage of forest area available in 2001 for further conversion. 
An additional issue we faced in this research was the role of outliers. When identifying the drivers of forest change, an outlier can lead to a weak or incorrect understanding of major drivers of change, and we must understand our study region fully in order to be able to identify this and to correct for it. Such is the case here with the city of Bangalore, and to a lesser extent the city of Mysore, representing such extremes in terms of population density when compared to the surrounding landscape and as such, overwhelming our regression models. This highlights the need for care while using models to understand or predict landscape change, and the need to develop a deeper landscape level understanding of the processes in order to spot such anomalous results and adapt our models to them.

Since humans are the primary agents responsible for forest change, population has therefore long been considered a major driver of environmental change [1,7]. Yet recent studies point out that these rather simplistic identifications fail to recognize the complexities of the relationship between humans and their environment $[4,5]$. For this region the distribution of stable forest cover appears influenced by population pressures of the past. However while deforestation is impacted by population density, this impact is to a lesser degree than in frontier landscapes, where most previous research on the human drivers of land use/land cover change have been carried out. Similar findings have been observed in the few studies that have been conducted on other long settled landscapes $[41,42]$. In this landscape, the availability of forest cover appears to be primarily determining the areas still left for further deforestation, as we found when we assessed the impact of drivers of forest change on deforestation expressed in two ways - as a percentage of the total area within districts and taluks, or as a percentage of the forest cover available for further conversion.

Other scholars reviewing a large number of case studies on deforestation and environmental change have similarly found that human processes have been a major driver of deforestation in recent years, but that linkages between population and forest decline are not straightforward and linear, and are moderated by many other critical variables, notably by institutions such as protected areas [15-18]. Recent research has been undertaken looking specifically at the role of parks and protected areas on land cover change, and especially on reforestation, regeneration or forest cover maintenance [11-13,43]. The research presented in this paper matches the findings of these other researchers, and finds that parks as institutions on the landscape, do preserve forest cover and decrease deforestation. Thus we find through the multiple regression model that the distribution of stable forest and deforestation calculated as a percentage of forest area in 2001 relates significantly to the area under protection in parks. These findings are also counter to some areas of the world where parks are more 'paper parks' and their impact on the landscape may be minimal, or even linked to higher rates of deforestation $[12,44]$.

Accessibility is the third variable assessed for its role in forest cover maintenance and deforestation for this study region. This emerges as a critical variable. It is the less accessible regions on this landscape which did manage to maintain their forest cover and are now being deforested, which simply reflects the availability of forested land for further clearing. The reason that areas with lower and less variable elevation are not part of this deforestation trend is that these regions have little forest left outside of protected areas. This trend is highlighted in the results of the multiple regression models where it is variation in elevation (along with the area under protection in parks) which is statistically significant in explaining the distribution of stable forest cover, while when explaining the distribution of deforestation the variables of elevation and variation in elevation are the most significant predictors. 
We find that the drivers of forest stability and change act in a largely similar manner at the scale of districts and taluks, reinforcing our confidence in identification of significant drivers of change. This is critical for policy assessments, because if drivers of forest stability and change were to act in a different manner at different spatial scales (as has been observed in some studies regarding population previously [4-6]), then this would have necessitated the adoption of more complex strategies for forest management.

As this analysis indicates, MODIS has the capacity to provide data at scales that are very appropriate, both spatially and temporally, for regional studies of land cover change, and has greatly improved the ability of land change scientists to conduct such regional studies of deforestation [28,30,45]. This research investigated the use of MODIS data for the study of deforestation and forest cover maintenance at a regional scale in southern India. With the incorporation of a multi-scalar dataset at different administrative scales - reflected as Districts $(n=8)$ and Taluks $(n=51)$, this study also allowed for a multi-scalar approach to the research question. It is noteworthy that, while there are many local-scale case-study type studies addressing the drivers of deforestation, there have been fewer studies looking at regional or even global scales [46]. This is a lack which needs to be addressed, and for which data such as MODIS and AVHRR can be the most appropriate data source for use. While past studies of land use/land cover change have relied predominantly on the use of the Landsat data products, at a regional scale, the current problems of sensor malfunction of Landsat 7, and a lack of available Landsat 5 data in some regions, has mandated a shift in focus to other data products and analysis methods. MODIS data are excellent to fill this gap, and are preferable to AVHRR as their spatial resolutions $(250 \mathrm{~m}, 500 \mathrm{~m}$ and $10,000 \mathrm{~m}$ ) allows researchers to link to the drivers of land use/land cover change which was not considered feasible with AVHRR data alone [47] and at the same time allow us to address regional studies of deforestation.

While local scale studies will undoubtedly continue, an increased emphasis on regional scale studies of land cover change allow for a better understanding of large scale drivers, such as protected areas and population. The research presented here serves as a clear example of the utility of such data and highlights the importance of the multi-scale approach, which has been present in ecological studies for decades e.g., hierarchical analysis, and yet has only recently begun to emerge in land change science research. MODIS, with its freely available data of moderate spatial and high temporal resolution across a large spectral range, should provide datasets critical for land change research in the coming decades-specifically for the study of both regional and global scale land cover characterization, monitoring and prediction [45,47].

Our analysis indicates that protected areas, population density, and landscape accessibility play a major role in driving forest protection, clearing and re-growth at different spatial scales. Such research has critical implications for policy as most effective management plans are developed at regional scales and it is critical that the scale of study should match scales of regional planning, in order that an appropriate level of understanding of how to deal with variations in biophysical, socioeconomic and institutional conditions within a region are incorporated into management plans. This study provides an example of how synergies between research and policy can be capitalized by studying landscape change at a scale (or scales) appropriate to policy management. Our findings on the major drivers of forest stability and change appear to hold at the scale of both districts and taluks, which represent the main administrative units within state boundaries wherein policies are implemented in India, and allow 
us to state our results with a higher degree of confidence that these can be applied across spatial scales within the region.

\section{Acknowledgements}

We acknowledge financial support from a Land Use Policy Information and Systems (LUPIS) grant from the European Union, from Society in Science: the Branco Weiss Fellowship, and from a Ramanujan Fellowship to HN from the Department of Science and Technology, Government of India. We thank Ramesh Kannan, Sham Kashyap, M. C. Kiran, Aravind Madhyastha, N. S. Prashanth, Bharath Sundaram and Abi Tamin for providing detailed inputs to assist our classification. We also thank two anonymous reviewers of this manuscript for their very useful comments on earlier drafts.

\section{References and Notes}

1. Turner, B.L., II; Lambin, E.F.; Reenberg, A. The emergence of land change science for global environmental change and sustainability. Proc. Nat. Acad. Sci. USA 2007, 104, 20666-20671.

2. Achard, F.; Eva, H.D.; Stibig, H.-J.; Mayaux, P.; Gallego, J.; Richards, T.; Malingreau, J.-P. Determination of deforestation rates of the world's humid tropical forests. Science 2002, 297, 999-1002.

3. DeFries, R.; Houghton, R.A.; Hansen, M.C.; Field, C.B.; Skole, D.; Townshend, J. Carbon emissions from tropical deforestation and regrowth based on satellite observations for the 1980s and 1990s. Proc. Nat. Acad. Sci. USA 2006, 99, 14256-14261.

4. Geist, H.J.; Lambin, E.F. Proximate causes and underlying driving forces of tropical deforestation. BioScience 2002, 52, 143-150.

5. Rudel, T.K. Changing agents of deforestation: from state-initiated to enterprise driven processes, 1970-2000. Land Use Policy 2007, 24, 35-41.

6. Allen, J.C.; Barnes, D.F. The causes of deforestation in developing countries. Ann. Assn. Amer. Geogr. 1985, 75, 163-184.

7. Ehrlich, P.R.; Ehrlich, A.H. The Population Explosion; Simon and Schuster: New York, NY, USA, 1990.

8. Nagendra, H.; Southworth, J.; Tucker, C.M. Accessibility as a determinant of landscape transformation in Western Honduras: Linking pattern and process. Landscape Ecol. 2003, 18, 141-158.

9. Fearnside, P.M. Containing destruction from Brazil's Amazon highways: now is the time to give weight to the environment in decision-making. Environ. Conserv. 2006, 33, 181-183.

10. Chomitz, K.M.; Gray, D.A. Roads, land use and deforestation: a spatial model applied to Belize. World Bank Econ. Rev. 1996, 10, 487-512.

11. Nepstad, D.; Schwartzman, S.; Bamberger, B.; Santilli, M.; Ray, D.; Schlesinger, P.; Lefebvre, P.; Alencar, A.; Prinz, E.; Fiske, G.; Rolla, A. Inhibition of Amazon deforestation and fire by parks and indigeneous lands. Conserv. Biol. 2005, 20, 65-73.

12. DeFries, R.; Hansen, A.; Turner, B.L.; Reid, R.; Liu, J. Land use change around protected areas: Management to balance human needs and ecological function. Ecol. Appl. 2007, 17, 1031-1038.

13. Nagendra, H. Do parks work? Impact of protected areas on land cover clearing. Ambio 2008, 37, 330-337. 
14. Ostrom, E.; Nagendra, H. Insights on linking forests, trees, and people from the air, on the ground, and in the laboratory. Proc. Nat. Acad. Sci. USA 2006, 103, 19224-19331.

15. Kaimowitz, D.; Angelsen, A. Rethinking the causes of deforestation: lessons from economic models. World Bank Res. Observ. 1999, 14, 73-98.

16. De Sherbinin, A.; Carr, D.; Cassels, S.; Jiang, L. Population and environment. Ann. Rev. Environ. Res. 2007, 32, 345-373.

17. Lambin, E.F.; Geist, H.J. Regional differences in tropical deforestation. Environment 2003, 45, 22-36.

18. Rudel, T.K. Tropical Forests: Regional Paths of Destruction and Regeneration in the Late 20th Century; Columbia University Press: New York, NY, USA, 2005.

19. Nagendra, H. Reforestation and regrowth in the human dominated landscapes of South Asia. In Reforesting Landscapes: Pattern and Process; Nagendra, H., Southworth, J., Eds.; Springer Landscape Series, Dordrecht, The Netherlands, 2009.

20. Ewers, R.M.; Laurance, W.F.; Souza, C.M., Jr. Temporal fluctuations in Amazonian deforestation rates. Environ. Conserv. 2008, 35, 303-310.

21. Mena, C.F.; Bilsborrow, R.E.; McClain, M.E. Socioeconomic drivers of deforestation in the northern Ecuadorian Amazon. Environ. Manag. 2006, 37, 802-815.

22. Wessels, K.J.; De Fries, R.S.; Dempewolf, J.; Anderson, L.O.; Hansen, A.J.; Powell, S.L.; Moran, E.F. Mapping regional land cover with MODIS data for biological conservation: examples from the Greater Yellowstone Ecosystem, USA and Pará State, Brazil. Remote Sens. Environ. 2004, 92, 67-83.

23. Scrieciu S.S. Can economic causes of tropical deforestation be identified at a global level? Ecol. Econ. 2007, 62, 603-612.

24. Cihlar, J. Land cover mapping of large areas from satellites: status and research priorities. Int. J. Remote Sens. 2000, 21, 1093-1114.

25. Han, K.-S.; Champeaux, J.-L.; Roujean, J.-L. A land cover classification product over France at $1 \mathrm{~km}$ resolution using SPOT4/VEGETATION data. Remote Sens. Environ. 2004, 92, 52-66.

26. Nagendra, H.; Rocchini, D. High resolution satellite imagery for tropical biodiversity studies: the devil is in the detail. Biodivers. Conserv. 2008, 17, 3431-3442.

27. Townshend, J.R.G.; Justice, C.O. Selecting the spatial resolution of satellite sensors required for global monitoring of land transformations. Int. J. Remote Sens. 1988, 9, 187-236.

28. Ferreira, N.C.; Ferreira, L.G.; Huete, A.R.; Ferreira, M.E. An operational deforestation mapping system using MODIS data and spatial context analysis. Int. J. Remote Sens. 2007, 28, 47-62.

29. Tucker, C.J.; Townshend, J.R.G. Strategies for tropical forest deforestation assessment using satellite data. Int. J. Remote Sens. 2000, 21, 1461-1472.

30. Huttich, C.; Gessner, U.; Herold, M.; Strohbach, B.J.; Schmidt, M.; Keil, M.; Dech, S. On the suitability of MODIS time series metrics to map vegetation types in dry savanna ecosystems: a case study in the Kalahari of NE Namibia. Remote Sens. 2009, 1, 620-643.

31. FAO. Global Forest Resources Assessment 2005: National Report No. 001: India; UN Food and Agriculture Organization: Rome, Italy, 2006.

32. Kamath, S.U. Karnataka State Gazetteer, Part 1; Government of Karnataka: Bangalore, India, 1982.

33. Kadekodi, G.K.; Kanbur, R.; Rao, V. Developments in Karnataka: Challenges of Governance, Equity and Empowerment; Academic Foundation: Bangalore, India, 2008. 
34. India Water Portal. Available online: http://www.indiawaterportal.org/data/basins/Cauvery/ Land\%20Use/ (accessed on August 2009).

35. Jensen, J.R. Introductory Digital Image Processing: A Remote Sensing Perspective, 2nd ed.; Prentice Hall: Upper Saddle River, NJ, USA, 1996.

36. Mücher, C.A.; Steinnocher, K.T.; Kressler, K.P.; Heuncks, C. Land cover characterization and change detection for environmental monitoring of pan-Europe. Int. J. Remote Sens. 2000, 21, 1159-1181.

37. Langner, A.; Mietinen, J.; Siegert, F. Land cover change 2002-2005 in Borneo and the role of fire derived from MODIS imagery. Glob. Change Biol. 2007, 13, 2329-2340.

38. Foody, G.M. Status of land cover classification accuracy assessment. Remote Sens. Environ. 2002, 80, 185-201.

39. Powell, R.L.; Matzke, N.; de Souza, C., Jr.; Clark, M.; Numata, I.; Hess, L.L.; Robertsa, D.A.; Clarka, M.; Numataa, I.; Hessc, L.L.; Robertsa, D.A. Sources of error in accuracy assessment of thematic land-cover maps in the Brazilian Amazon. Remote Sens. Environ. 2004, 90, 221-234.

40. Sokal, R.R.; Rohlf, F.J. Introduction to Biostatistics, 2nd ed.; Island Press: Washington, DC, WA, USA, 1981.

41. Etter, A.; Wyngaarden, W.V. Patterns of landscape transformation in Colombia, with emphasis in the Andean region. Ambio 2000, 29, 432-439.

42. Young, K.R. Stasis and flux in long inhabited locales: change in rural Andean landscapes. In Land Change Science in the Tropics: Changing Agricultural Landscapes; Millington, A., Jepson, W., Eds.; Springer: New York, NY, USA, 2008.

43. Hartter, J.; Southworth, J.; Binford, M. Parks as a mechanism to maintain and facilitate recovery of forest cover: examining reforestation, forest maintenance and productivity in Uganda. In Reforesting Landscapes: Pattern and Process; Nagendra, H., Southworth, J., Eds.; Springer Landscape Series: Dordrecht, The Netherlands, 2009.

44. Schwartzman, S.; Moreira, A.; Nepstad, D. Rethinking tropical forest conservation: perils in parks. Conserv. Biol. 2000, 14, 1351-1357.

45. Townshend, J.R.G.; Justice, C.O. Towards operational monitoring of terrestrial systems by moderate-resolution remote sensing. Remote Sens. Environ. 2002, 83, 351-359.

46. Lambin, E.F.; Geist, H.J.; Lepers, E. Dynamics of land-use and land-cover change in tropical regions. Ann. Rev. Environ. Res. 2003, 28, 205-241.

47. Hays, D.J.; Cohen, W.B.; Sader, S.A.; Irwin, D.E. Estimating proportional change in forest cover as a continuous variable from multi-year MODIS data. Remote Sens. Environ. 2008, 112, 735-749.

(C) 2010 by the authors; licensee Molecular Diversity Preservation International, Basel, Switzerland. This article is an open-access article distributed under the terms and conditions of the Creative Commons Attribution license (http://creativecommons.org/licenses/by/3.0/). 